\title{
Delivery of drugs and macromolecules to the mitochondria for cancer therapy
}

Phong Lu a, Benjamin J. Bruno a, Malena Rabenau b, and Carol S. Lim a, ${ }^{*}$

a Department of Pharmaceutics and Pharmaceutical Chemistry, College of Pharmacy, 30 S. 2000 E.,

University of Utah, Salt Lake City, Utah, 84112 USA

b Department of Pharmaceutics and Biopharmacy, Phillips-Universität, 35037 Marburg, Germany

* Corresponding author at: Department of Pharmaceutics and Pharmaceutical Chemistry, College of

Pharmacy, 30 S. 2000 E. \#2916, University of Utah, Salt Lake City, Utah, 84112, USA. Ph 801587-9711,

fax 801-585-3614. Email: carol.lim@pharm.utah.edu 


\section{Mitochondria as a target for cancer therapy}

Known as the ATP-generating powerhouse of the cell, mitochondria are also at the center of the programmed cell death pathway. Due to their essential roles in cellular function and physiology, mitochondria alteration is the hallmark of oncogenesis, tumor progression, angiogenesis, and chemotherapy resistance [1-3]. The malignant transformation of tumor cells are often the result of long term damage caused reactive oxygen species (ROS), which is the toxic byproduct of oxidative phosphorylation [4]. Mitochondria also house many pro-apoptotic and anti-apoptotic proteins such as Bax, Bak, Noxa, Bcl-XL, and Bcl-2. Altered expression of these proteins is implicated in cell survival mechanisms and drug resistance $[5,6]$.

The roles of the mitochondria in cancer and many other diseases have been widely recognized in the last 10 years, and a plethora of potential agents (both small molecules and macromolecules) that act on mitochondrial targets have been reported in many published papers [1-8]. However, effective delivery of these agents to the mitochondria poses many challenges for these therapies to come to fruition. This review will focus on current and upcoming mitochondrial targeting strategies.

\section{Mitochondria structure, function, and role in apoptosis}

\subsection{Structure of mitochondria and ATP production}

Mitochondria are discrete organelles present in most eukaryotes with a few notable exceptions such as mammalian erythrocytes [9]. The structure of mitochondria can be grossly divided into four compartments: the outer mitochondrial membrane (OMM), the intermembrane space (IMS), the inner mitochondrial membrane (IMM), and the mitochondrial matrix (Fig.1). The inner membrane is highly invaginated to create cristae (Fig. 1), which provides increased surface area for ATP production $[9,10]$. As is well known, ATP is an energy source that is transported within cells during metabolic processes. The major mechanisms of ATP biosynthesis occur via cellular respiration (oxidative phosphorylation), photosynthesis (photophosphorylation in plants), and substrate level phosphorylation. Although ATP can be produced by different processes such as glycolysis, oxidative phosphorylation produces most of the cellular ATP. The electron transport chain including ATP synthase (the enzyme responsible for synthesizing ATP from ADP and inorganic phosphate) is found on the inner membrane.

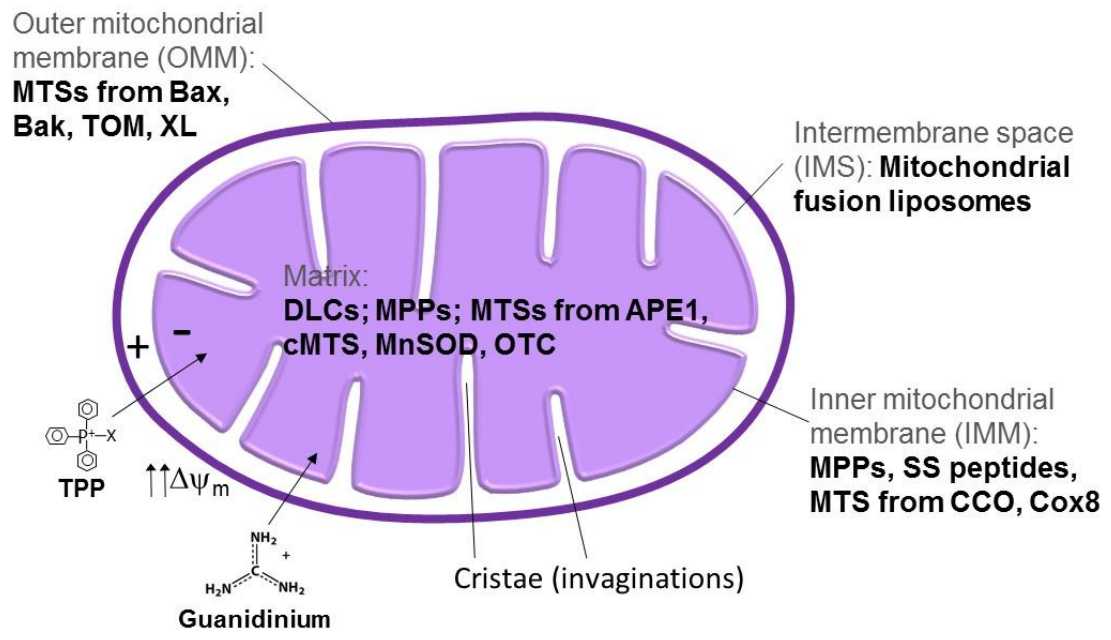


Fig. 1. Sub-compartmentalization of mitochondriotropic agents discussed in this paper (when known). The high membrane potential across the mitochondria $\left(\Delta \psi_{\mathrm{m}}\right)$ allows for the accumulation of guanidinium and DLCs such as TPP into the mitochondria.

The intermembrane space (peripheral space and intracristal space) has an acidic environment, and a proton gradient between the IMS and matrix is maintained by the electron transport chain. As the electrons are passed from NADH to oxygen through the OXPHOS system, the electrons lose energy at each step, and this energy is used to pump protons from the mitochondrial matrix to the intermembrane space via NADH dehydrogenase (complex I), $\mathrm{CoQH}_{2}$-cytochrome c reductase (complex III), and cytochrome c oxidase (complex IV) [11] (Fig. 1). The proton gradient is utilized to drive the conversion of ADP to ATP by ATP synthase (complex V), while simultaneously pumping protons from the intermembrane space back to the matrix $[11,12]$. Details about the electron transport chain and ATP production have been discussed extensively elsewhere [13, 14].

The mitochondrial matrix includes the inner boundary membrane, and encloses matrix granules, mitochondrial DNA, and ribosomes. The matrix is also involved in the lipid oxidation process. The breakdown of fatty chains by $\beta$-oxidation to generate acetyl-CoA, which feeds into the citric acid cycle, occurs within the mitochondrial matrix. The transport of the fatty acid into the mitochondrial matrix is the first step of this metabolic pathway [15]. This transport is controlled by the carnitine palmitoyltransferase (CPT) system, including CPT1, acylcarnitine translocase (CACT), and CPT2 $[15,16]$. Malonyl-CoA, which is synthesized by acetyl-CoA carboxylase, is known to have an inhibitory effect on CPT1 [16].

In humans, the mitochondrial matrix contains multiple copies of circular double stranded DNA, about $16.6 \mathrm{~kb}$ in size. Each mtDNA molecule encodes 13 proteins, 22 tRNAs, and 2 rRNAs required for the translation of these proteins in the mitochondria [17, 18]. These 13 hydrophobic proteins function in oxidative phosphorylation (OXPHOS). However, not all of the proteins of the electron transport system are encoded in the mitochondria; most are encoded in the nucleus [18]. The nucleus is also responsible for proteins that participate in the maintenance of the mitochondria such as mitochondrial transcription factor A (TFAM) [19]. Mutation of mtDNA has been implicated in many genetic diseases including cancer, diabetes, and KearnsSayre syndrome $[18,20]$.

Although the structure of mitochondria can be grossly divided into four compartments like an isolated organelle, it should be noted that mitochondria form a functional reticulum structure, and mitochondria are highly dynamic organelles [21, 22]. Their morphology, distribution, and activity are constantly regulated. Remodeling of mitochondria by fusion and fission machineries has been comprehensively reviewed elsewhere [21-24].

\subsection{Role of the mitochondria in programmed cell death}

Cell death can be separated into two broad categories: necrosis and apoptosis. Necrosis is traditionally regarded as the result of cellular damage and injury. Necrosis involves cell swelling, followed by the rupture of the plasma membrane and the uncontrolled release of the cell's contents. Necrosis comes from the term "oncosis" (meaning swelling) and was used as a term for "cell death opposite to apoptosis" [25]. A subset of necrosis, termed necroptosis, is also a form of regulated cell death [26-29]. Necroptosis does not involve the activation of the caspase pathway. Instead, it is triggered through the activation of death receptors such as TNFR by ligands or stimuli. RIP1 and RIP3 are kinases that are required for the activation of necroptosis through death receptors $[27,30,31]$. Subsequently, the death signal requires activation of mixed 
lineage kinase domain-like (MLKL) by RIP3 kinase through phosphorylation [28]. While the role of mitochondria in necroptosis has not fully been delineated, the mitochondrial phosphatase PGAM5 has been reported to be the convergence point of multiple necrosis pathways [29].

On the other hand, programmed cell death (apoptosis) is a tightly regulated pathway that involves caspase activation. Apoptosis is characterized by condensation of chromatin, fragmentation of chromosomal DNA, and membrane blebbing [32]. DNA damage by cytotoxic drugs activates the intrinsic apoptotic pathway, which is governed by the mitochondria. Apoptosis is triggered through a sequence of mitochondrial events including the collapse of the inner membrane potential, swelling of the mitochondria, and opening of the permeability transition pore. Mitochondrial outer membrane permeabilization (MOMP), generally regarded as "the point of no return" [32,33], leads to the release of cytochrome c, second mitochondriaderived activator of caspase (Smac), apoptosis-inducing factor (AIF), and other apoptotic factors [34]. Cytochrome $\mathrm{c}$ is a cofactor for the apoptotic protease-activating factor-1 (APAF-1) [32], and activation of APAF-1 facilitates the formation of the apoptosome, which, in turn, activates caspase 9. The whole cytC/APAF-1/Caspase 9 complex triggers the downstream caspase cascade that eventually leads to apoptosis $[35,36]$.

The mitochondria houses many proteins that either directly or indirectly trigger MOMP. The B-cell lymphoma 2 (Bcl-2) family is the major modulator of cell death [33]. The members of this family are identified by having one or more of the four Bcl-2 homology domains (BH14). Pro-apoptotic factors such as PUMA, Bad, Noxa, Bid, and Bim are BH3-only proteins, while anti-apoptotic factors such as Bcl-2, Bcl-XL, and Mcl-1 have four BH domains [33]. Bak, Bax, and Bok are the three pro-apoptotic factors that have $\mathrm{BH} 1$ and $\mathrm{BH} 2$ domains in addition to the BH3 domain. Notably, Bak and Bax are the two primary activators of MOMP. While Bak constitutively localizes at the outer membrane, $\mathrm{Bax}$ is a cytosolic protein that translocates to the OMM when activated [33]. Upon receiving apoptotic stimuli, oligomerization of Bak and Bax proteins form permeable pores. Mutagenesis and structural studies have provided many insights into how Bax and Bak interact with other proteins. Bax and Bak oligomerization is the result of a major change in their structural conformation induced by their interaction with other BH3-only proteins or through direct interaction with p53 [37]. Bax and Bak have nine alpha helices spanning the entire molecule including the $\mathrm{BH} 3, \mathrm{BH} 1, \mathrm{BH} 2$, and a transmembrane domain on the C-terminus. The alpha helix 2-5 region encompassing the $\mathrm{BH} 3$ and $\mathrm{BH} 1$ domains is the most important region for cell death activation [38]. In non-apoptotic cells, the BH3 domain of Bak is buried in the core of the protein. The exposure of this $\mathrm{BH} 3$ domain is required for the oligomerization and cell death activation [38].

Interestingly, the size of the pores are tunable depending on the concentration of the cBid (cleaved Bid)-activated Bak and Bax [39]. Cardiolipin, a unique phospholipid found on the mitochondrial membrane, also affects the rate of pore formation by influencing the rate of Bax insertion to the OMM [39], hence playing a role in MOMP. Cardiolipin is additionally known to not only help maintain the fluidity and the shape of the inner membrane but also maintains the function of OXPHOS proteins [40]. Further, the presence of cardiolipin may be crucial to the activation of Bax and Bak [41, 42].

Bak and Bax knockout cells have prolonged survival in the absence of growth factors [43]. Cells without both Bak and Bax are especially resistant to tBid (truncated Bid, one of the fragments of cBid) induced apoptosis [44]. Bcl-XL and Bcl-2 sequester BH3-domain-only members of the Bcl-2 family and prevent them from initiating MOMP [45, 46]. Noxa, Bim, and Bad have been noted to be relatively weak pro-apoptotic factors. However, they have a crucial 
role in regulating apoptosis. Particularly, Noxa is known to target anti-apoptotic factors such as Mcl-1 for proteasomal degradation [47]. Therefore, Noxa, Bim, and Bad may indirectly activate Bax and Bak through their interaction with anti-apoptotic factors [48]. However, a recent study using fluorescence complementation has revealed a direct interaction of Noxa, Bim, and PUMA with Bak and Bax in apoptosis induction [49].

In many cases, MOMP is also regulated by the inner membrane through the transmembrane potential $\left(\Delta \Psi_{\mathrm{m}}\right)$. Notably, the inner membrane can also induce MOMP through the mitochondria pore transition complex (MPT complex) [2, 32]. The MPT complex includes the voltage-dependent anion channel (VDAC) on the outer membrane, the adenine nucleotide translocase (ANT) on the inner membrane, and cyclophilin on both membranes and the matrix $[2,32]$. The presence of the VDAC in its low conductance state (low permeability to ions) makes the outer membrane of mitochondria permeable to metabolites up to $5 \mathrm{kDa}$ [50]. Upon apoptotic stimuli such as $\mathrm{Ca}^{2+}$ release during ER stress, VDAC may adopt a high conductance state which triggers mitochondrial permeability transition [50]. MPT is characterized by the loss of the transmembrane potential $\left(\Delta \Psi_{\mathrm{m}}\right)$ and the flux of water, ions and other molecules into the matrix, leading to mitochondrial matrix swelling [32]. Because the IMM has a larger surface than the OMM, the swelling of the matrix will eventually lead to OM rupture and MOMP [32, 50]. VDAC2 has been reported to interact and inhibit Bak, while BH3-domain-only molecules such as tBid, Bim, and Bad may displace VDAC2 and activate Bak oligomerization [51]. In another study in a myocardial infarction mouse model, cells that have a Bak/Bax deletion are resistant to necrosis and MPT [52]. Reconstitution of these cells with oligomerization-deficient Bax can restore MPT and necrosis. Therefore, Bax monomer may be sufficient for mediating necrosis although it is unable to mediate apoptosis [52]. The release of cytochrome c, AIF, and endonuclease $\mathrm{G}$ also seems to be affected by the inhibition of an IMM potassium channel mitoKv1.3 by Bax [53]. In summary, the intrinsic apoptosis pathway is a highly regulated pathway with the interplay of many anti-apoptotic and pro-apoptotic factors. Bax and Bak are the two principal proteins that oligomerize to form OMM pores, which lead to MOMP.

\subsection{Mitophagy}

Mitophagy describes the process of selective degradation and elimination of the damaged mitochondria. Mitophagy helps maintain intracellular homeostasis and is essential to the wellbeing of the cells [54]. As the site for ATP production, mitochondria are especially susceptible to damage caused by ROS. Damaged mitochondria not only have reduced ATP production efficiency but also increase the risk of undesired release of cytochrome $\mathrm{c}$ and other mitochondrial contents. In addition, faulty mitochondria can be a major source of ROS itself. It has been speculated that insufficient mitophagy may contribute to oncogenesis [54-57]. Bcl-XL, an antiapoptotic factor often up-regulated in many types of tumors, also suppresses mitophagy [58]. Factors implicated in mitophagy include Parkin, PINK1, BNIP3, NIX and others [55, 59]. It is not surprising that Parkin, an E3 ubiquitin ligase that ubiquitylates mitochondrial proteins in damaged mitochondria and triggers mitophagy, is a tumor suppressor protein [56, 57]. Parkin is recruited by PTEN-induced putative kinase protein 1 (PINK1). Notably, the N-terminal 30 amino acids of PINK1 have been identified to be a mitochondrial matrix targeting signal [60]. However, in damaged mitochondria, the depolarization of the mitochondria potential reduces PINK1 matrix import, while promoting PINK1 accumulation at the outer mitochondrial membrane (OMM), using the PINK1 OMM targeting signal located at residues 70 to 94 [60]. The details of 
the mitochondrial targeting of these proteins may be of interest for drug delivery. It is also known that loss of Parkin results in formation of liver tumors and stimulates the Warburg Effect [59]. In addition to cancers, mutations of these mitophagic proteins have been also associated with Parkinson's disease [57, 61]. Mitophagy occurs also in response to hypoxia, and BNIP3 and NIX proteins have been found to promote this type of autophagy, with particular tissue specificity [59]. BNIP promotes mitophagy in liver and skeletal muscle, and NIP promotes mitophagy in reticulocytes. Interestingly, BNIP and NIX levels are higher in certain breast cancers. This emerging area (reviewed in [59]) indicates that there may be high potential of targeting mitophagy as a therapeutic strategy for diseases like cancer.

\subsection{Targeting of proteins to mitochondria}

To target a protein to mitochondria, an understanding of mitochondrial protein transport is necessary. There are two main mechanisms for transporting proteins to organelles in eukaryotes: co-translational transport and post-translational transport [62, 63]. In the first case, the translocation of the protein is coupled with translation. In the second case, the transport of the precursor protein is guided by a cytosolic chaperone. The transport of mitochondrial proteins is post-translational [62].

Most proteins that are targeted to the mitochondria have a mitochondrial targeting sequence (MTS). Depending on the specific targeting signal, the destination of that protein may be the OMM, IMM, or the mitochondrial matrix (Fig. 2, Table 1). This MTS can be found anywhere in the polypeptide sequence. However, about half of these MTS reside near the Nterminus of the protein [64]. In some instances, the MTS is found on the C-terminus of the protein. Examples of C-terminal MTSs include the MTS of helicase Hmi1p and the MTS of human apurinic/apyrimidinic endonuclease 1 (Ape1) $[65,66]$. Tail-anchored proteins have a Cterminal sequence with moderate hydrophobicity (transmembrane segment), and is flanked by positively-charged amino acids [67]. While tail-anchored proteins are known to generally insert into the mitochondrial outer membrane, the mechanism of insertion/targeting is yet to be fully elucidated, although 10+ proteins are now thought to be involved in the process [68].

While the MTS of mitochondrial proteins do not have a conserved sequence, some have a propensity to form an amphiphilic helix with one positively charged surface and one hydrophobic surface [64, 69] (Fig. 2A). Specifically, it is thought that an amphipathic helix is required for transport to the matrix [68]. After the proteins are transported into the mitochondrial matrix, the MTS sequence in some proteins is cleaved by proteases [64] (with other reported non-cleavable MTSs as well [64, 69]). The cleavability of these MTS, although not well understood, determines how the protein is transported into mitochondria. For example, Nterminal cleavable MTS sequences are transported through the heterodimer receptors of TOM20 and TOM 22 on the OMM (Fig. 2A), while non-cleavable MTSs appear to require the addition of TOM70 [66, 70] (Fig. 2B, C, D). Signal anchored, tail anchored, or $\beta$-barrel proteins are targeted to the OMM (Fig. 2D). Some internal signal sequences may function with a nearby hydrophobic region for IM targeting [71] (Fig. 2B). More details about these MTS and their corresponding destination can be found in many reviews $[62,71]$. A select subset of MTSs can be found in Table 1.

The TOM complex (translocase of the outer membrane of mitochondria), as shown in Fig. 2, is responsible for the transport of proteins through the mitochondrial outer membrane into the intermembrane space (IMS) [62-64, 71]. TOM40 is an integral membrane protein that 
functions as an oligomer of two to three channels. TOM 40 makes up the central component of the TOM complex [72]. TOM 40 is assisted by TOM20, which recognizes the presequence of the proteins. The presequence of TOM20 has been reported to have a dynamic conformation and multiple interaction modes that help accommodate the diversity of different mitochondrial presequences [73]. TOM20 transfers the presequence to the central receptor TOM22 [71]. In addition to TOM20, TOM70 is another recognition site for the precursor proteins. However, the precursor proteins recognized by TOM70 often carry internal sequences, and their destination is the inner membrane [71].

For $\beta$-barrel precursor proteins that are destined to the OMM, the tiny TIM proteins help deliver these proteins through the IMS to the SAM complex for insertion into the OM after they traverse the TOM complex (Fig. 2D). If the precursor proteins are targeted for IMS localization, the mitochondrial IMS import and assembly (MIA) complex (including Mia40 and Erv1) facilitates the transport and assembly of these proteins in the IMS [62, 74] (Fig. 2C. bottom right).

The TIM complex (translocase of the inner membrane of mitochondria), as shown in Fig. 2 , is responsible for the transport of proteins destined for inner membrane and matrix. TIM23 is central to the TIM complex and forms the membrane channel core with TIM17, TIM21 and TIM50 [64]. The TIM23 complex is associated with the motor PAM protein, built surrounding the mitochondrial chaperone heat shock protein 70 ( $\mathrm{mtHsp} 70)$, which utilizes ATP hydrolysis to drive the translocation of the precursor proteins into the matrix [71, 75]. TIM9 and TIM10 assist the transfer of the precursor protein to the Tim22 complex for insertion into the inner membrane [76]. Tim 22 receives energy from the electrochemical potential across the inner membrane [71, 76] (Fig. 2B). In general, the characteristics of the MTS and the location of the MTS in the proteins are critical for specific targeting of proteins to the mitochondria. Utilization of specific MTSs as a promising targeting strategy will be discussed in Section 5.4 and 6. 


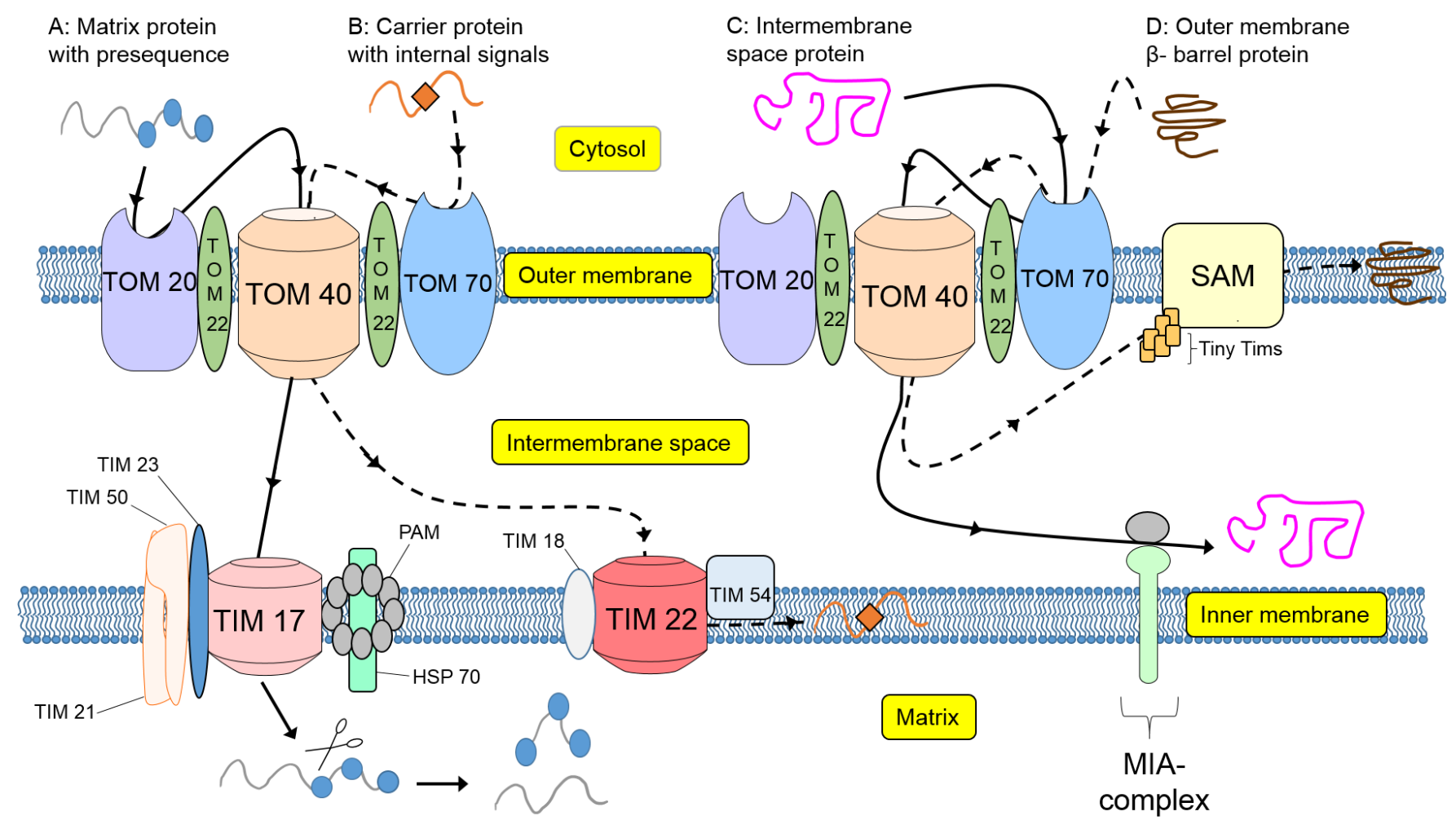

Fig. 2. Mitochondrial import mechanisms. For details, see text.

\section{The relevance of mitochondria in cancer}

\subsection{Production of reactive oxygen species}

Mitochondria are the main source of ROS, the toxic byproduct of oxidative phosphorylation [77]. Prolonged exposure to increased ROS production is a major cause of cellular damage, which is linked to many malignant processes. Oxidative stress may induce cellular senescence and death. One way ROS can encourage cell death is via the association of cardiolipin with cytochrome c; ROS promote cardiolipin peroxidation, which allows the dissociation of cardiolipin from cytochrome $\mathrm{c}$ and its subsequent release [78]. ROS overproduction appears to promote mutations of oncogenes. When mutated cells survive this oxidative stress, they may emerge as immortalized cells and initiate tumor progression [4]. The activity of some tyrosine kinases and phosphatases depends on the levels of ROS, specifically $\mathrm{H}_{2} \mathrm{O}_{2}$. For example, Src tyrosine kinases are activated when two cysteine residues are oxidized [79]. Production of ROS in mitochondria is also associated with the RAS oncogene since RAS induces the expression of many mitochondrial proteins such as NRF-2, PGC-1 $\alpha$, and TFAM [4]. There is evidence that ROS also mediates the unusual activity of hTERT (human telomerase) in cancer cells, and the overexpression of hTERT also inhibits ROS-induced apoptosis [80, 81]. Human telomerase activation is one of the major hallmarks of cancer [80, 81].

Mitochondria have an antioxidant defense system whereby ROS are detoxified by many enzymes including glutathione peroxidase, superoxide dismutase, and catalase [82]. However, 
excessive production of ROS may exceed the capacity of the antioxidant defense system. Superoxide, a form of ROS, can be converted into other hydroxyl radicals, which have been linked to degenerative disorders such as amyotrophic lateral sclerosis (ALS) [83]. Many antioxidants like vitamin $\mathrm{C}$ and vitamin $\mathrm{E}$ may help scavenge free radical species, and targeting antioxidants to the mitochondria has been of great interest to prevent mitochondrial oxidative damage [75, 84, 85].

Due to the proximity of the mtDNA to the site of oxidative phosphorylation, mtDNA is especially vulnerable to ROS damage. There are many studies on the correlation of mtDNA mutation and cancer progression. Although the precise link between mtDNA and cancer is unclear, mutated mtDNA has been found in leukemia, colorectal, head and neck, bladder, and lung cancer [18, 86-88]. It is unknown if these mutations actually contribute to the development of tumors or simply are the result of damage by long term exposure to ROS. However, since mtDNA codes for OXPHOS proteins, defects in these proteins may increase ROS production [12].

\subsection{The Warburg effect}

The Warburg effect describes the metabolic difference between cancer cells compared to normal cells. The Warburg effect shows that cancer cells have higher rates of glycolysis (to produce ATP) even when there is enough $\mathrm{O}_{2}$ present. Although this aerobic glycolysis process yields less ATP than oxidative phosphorylation, it provides precursors for the synthesis for amino acids and biomolecules required for anabolic processes [9, 89].

Rapidly dividing tumor cells are often exposed to hypoxia due to the lack of sufficient oxygen to accommodate the proliferation of these cancer cells. One reason cancer cells are resistant to hypoxia-induced cell death is due to alteration of their p53 status [89, 90]. Under hypoxia, cancer cells upregulate hypoxia-inducible factor 1 (HIF-1). HIF-1 can upregulate many other pathways including angiogenesis and glycolysis to promote cell survival. HIF-1 activation switches the oxidative phosphorylation process to glycolysis by controlling the fate of pyruvate [89]. Particularly, HIF-1 turns on pyruvate dehydrogenase kinase 1 (PDK1), which can phosphorylate and shut down pyruvate dehydrogenase (PDH), the enzyme that catalyzes the first step of the TCA (tricarboxylic acid) cycle. At the same time, HIF-1 also turns on lactate dehydrogenase, which converts pyruvate into lactate. The production of lactate is coupled with the generation of $\mathrm{NAD}^{+}$, which is used to maintain glycolysis [89].

While tumor cells are under hypoxia, one may expect cells to produce less ROS, but surprisingly, these cells actually have increased ROS. The production of ROS is dependent on the concentration of the reduced respiratory chain complex, which is higher under hypoxic conditions [89, 91]. Therefore, HIF-1 expression is also correlated with ROS production [89].

Additionally, HIF-1 also upregulates hexokinase (HK). Hexokinase associates with VDAC on the mitochondrial outer membrane, and this association can inhibit permeability pore transition. Notably, protein kinase B (Akt) is a modulator of this HK/VDAC association. Disrupting this association may promote mitochondrial permeability transition [2, 92, 93]. Additionally, Akt can also activate NF- $\mathrm{BB}$, which in turn phosphorylates and inhibits proapoptotic Bad to promote cell survival [94].

\subsection{Transformation of mitochondria in cancer to adapt to oncogenic stress}


It has been reported that many cancers adapt to oncogenic stress via mitochondrial pathways. Such is the case with pancreatic ductal adenocarcinoma (PDAC), a nearly incurable cancer with a very high mortality rate. KRAS mutation is a key driver in PDAC and also a promising target for cancer therapy. However, a population of PDAC still survives after the KRAS pathway is shut down. Interestingly, KRAS ablation-resistant PDAC cells have been reported to be dependent on oxidative phosphorylation for their survival [95]. The switch from the glycolyticdependent state to the OXPHOS-dependent state suggests that a combination of OXPHOS inhibitors with oncogenic pathway inhibitors may be effective against PDAC [95]. A similar observation has been reported for acute myelogenous leukemia (AML) [96, 97]. Many other oncogenes besides KRAS have a role in malignant mitochondria and have been extensively reviewed elsewhere $[2,4,9]$.

\subsection{Upregulation of anti-apoptotic factors in cancer}

Mitochondria also have an important role in chemotherapy resistance. Cancers are often resistant to many types of chemotherapy drugs, irrespective of the mechanism of action [98]. Since many anti-cancer drugs work through the intrinsic apoptosis pathway, the Bcl-2 family may have a significant effect on the outcome of chemotherapy [98]. The apoptotic threshold of a tumor is known to correlate with its clinical response to chemotherapy. Mitochondrial priming is the apoptotic threshold of a tumor as measured by the challenge of that tumor to synthetic $\mathrm{BH} 3$ derived pro-apoptotic peptides. Of significance, chemosensitive tumors have higher mitochondrial priming than their chemoresistant counterparts [98].

Some examples of upregulated anti-apoptotic proteins in cancers are as follows. High expression of BH3-only proteins (Bid, Bim, Bad, Puma, and Noxa) is associated with better prognosis in colon cancer [99]. High expression of Bak and low expression of Bcl-2 correlate with a better apoptotic profile in invasive ductal breast carcinomas [100]. In contrast, overexpression of anti-apoptotic Bcl-2 and Bcl-XL is known to block caspase activation and apoptosis [3, 6, 101]. Overexpression of $\mathrm{Bcl}-2$ is linked to prostate cancer androgenindependence $[102,103]$. Overexpression of Mcl-1, another anti-apoptotic protein in the Bcl-2 family is associated with poor prognosis in ovarian cancer [104].

The importance of the Bcl-2 family has led to the development of many $\mathrm{BH} 3$ mimetics that can bind and inhibit Bcl-2 and Bcl-XL. ABT-737 is arguably the best known and wellcharacterized small molecule that targets Bcl-2 [2, 97]. By inhibiting Bcl-2 and Bcl-XL, ABT737 allows for the activation of Bax and Bak. Induction of apoptosis by ABT-737 is Bak/Bax dependent (via the intrinsic apoptotic pathway). However, ABT-737 does not neutralize Mcl-1. Overexpression of Mcl-1 is a major mechanism of cancer cell resistance to ABT-737 treatment [105-107]. Conversely, increased Noxa expression can overcome Mcl-1-induced ABT-737 resistance in leukemia [108]. The development of Bcl-2 inhibitors and Bak/Bax inducers indeed represent a new class of chemotherapeutics.

\subsection{Mutated p53 fails to trigger Bax and Bak oligomerization}

The tumor suppressor p53 is often regarded as the guardian of the genome. Although the main function of p53 is as a transcription factor in the nucleus, p53 also plays an important role in the mitochondria. Independent of its nuclear functions, p53 is known to directly bind to Bax and Bak proteins to trigger their oligomerization and induce MOMP [37] [109, 110]. Binding of p53 to 
Bak requires specific amino acid residues in the DNA binding domain (DBD) of p53 [111]. Notably, this DBD domain is often mutated in cancer and impairs the ability of p53 to bind Bax/Bak [111]. Targeting p53 to mitochondria is a novel approach to directly trigger apoptosis $[112,113]$. Furthermore, p53 also participates in the DNA-repair pathway in the mitochondria during oxidative stress. Many binding partners of p53 in this process have been identified [114].

In summary, mitochondria are organelles with pivotal roles in producing energy necessary for life and executing the cell death pathway. Mitochondrial aberration is at the center of cancer progression and chemosensitivity. Efforts in mitochondrially targeted therapy will focus on reducing oxidative stress and reactivating intrinsic apoptosis. For many metabolic disorders, restoring the function of the enzymes in OXPHOS or fatty acid oxidation (FAO) is highly desirable. The remainder of the review will discuss different strategies of mitochondrial delivery including delivery using small molecules, peptides, genes encoding proteins and MTSs, and targeting polymers/nanoparticles with payloads to the mitochondria (Fig. 3). The advantages and disadvantages for each strategy will be discussed, as well as future perspectives for targeting drugs and macromolecules to the mitochondria for cancer therapy.

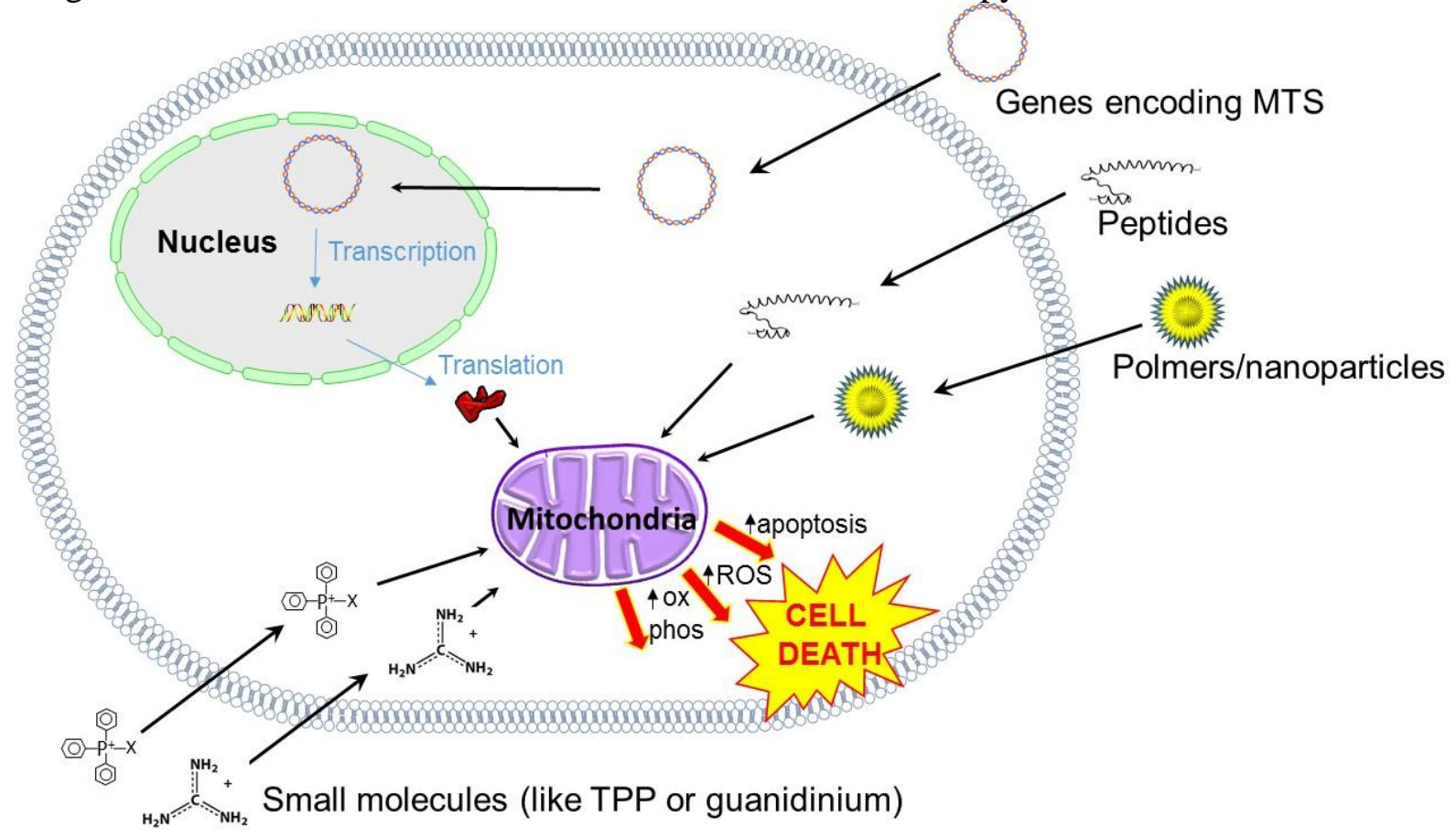

Fig. 3. Drugs and macromolecules that target the mitochondria for cancer therapy.

\section{Small molecules for delivery to the mitochondria}

\subsection{Delocalized lipophilic cations (DLCs)}

Delocalized lipophilic cations (DLCs) are small molecules that carry a single delocalized positive charge (Fig. 1) [115]. Some DLCs, including Janus green and rhodamine 123, have been around since the late 1980s, although the mechanism of mitochondria targeting was not elucidated until much later [115]. Their lipophilic nature and resonance-stabilized delocalization of the charge allows the molecules to easily pass through phospholipid bilayers [115]. Further, due to their large ionic radius, DLCs are easily desolvated, thus lowering the enthalpy associated with desolvation upon entering a lipid environment [116]. As a class, more lipophilic DLCs tend 
to have higher mitochondrial accumulation, and the more hydrophobic the DLC, the more likely it is to locate in the matrix, bound to the inner mitochondrial membrane [115].

Due to their positive charge, DLCs accumulate first within the cell and then preferentially in the mitochondria, as predicted by the Nernst equation; DLPs accumulate in the cytoplasm and mitochondria at 10 times and 100-1000 times the concentrations the compounds are found in the extracellular environment, respectively [115]. Due to the higher plasma and mitochondrial membrane potentials of some carcinomas, DLCs may be useful for tumor-specific delivery of therapeutics [117]. In vivo, triphenylphosphonium (TPP), the prototypical DLC (Fig. 1), is taken up by mitochondria within a matter of minutes, and is preferentially taken up by cells of the heart, liver, kidneys, and, to a lesser extent, the brain [115].

As the chemical conjugation of DLCs to cargo is a relatively simple procedure, they have been used for mitochondrial delivery of a variety of cargos, including antioxidants, nucleic acids, and spin traps [115]. Commercially available DLCs including Mitotracker ${ }^{\mathrm{TM}}$ and TPP are commonly used as mitochondria-specific staining agents in studying mitochondrial physiology. However, use of DLCs is limited by both toxicity and the types of cargo they can deliver; while being good carriers for lipophilic or small polar molecules, DLCs are less effective at delivering large, polar molecules. This is likely because the charge of the larger molecule overwhelms the mitochondria-targeting characteristics of the (relatively) smaller DLC. Further, many DLCs are toxic to mitochondria at high concentrations [117], although others believe the self-limiting nature of mitochondrial accumulation will minimize in vivo toxicity [115].

\subsection{Guanidine-based vehicles}

Guanidine, the functional group of the amino acid arginine, was first noted for its role in cell permeation as a component of the arginine- and lysine-rich cell-penetrating peptide TAT [118]. Researchers were able to demonstrate that guanidine, unlike the ammonium group of lysine, was able to form a bidentate hydrogen bond with the phosphates, carboxylates, and/or sulfates of the cell surface [118]. Founded on these results, guanidinium-based small molecules (Fig. 1) and peptides have been designed for cell permeability and mitochondria-specific delivery of therapeutic agents. Two such tetraguanidinium compounds were synthesized from chiral bicyclic guanidinium subunits, linked by a thioester bond. These compounds demonstrated both cell permeability and rapid mitochondrial colocalization (in less than 5 minutes in vitro), although the more lipophilic of the two compounds showed improved mitochondrial localization [119]. Previous work had shown that similar compounds formed stable complexes with negativelycharged proteins, so it is possible that tetraguanidinium compounds could be used to deliver proteins across both the plasma and mitochondrial membranes [119]. Further iterations of this system have been developed for the delivery of covalently attached small molecules and peptide/protein drugs, including adjustable lipophilicity of the compound, for optimized mitochondrial delivery [120]. Indeed, gamitrinib covalently attached to a tetraguanidinium vehicle resulted in efficient mitochondrial delivery and inhibition of HSP90 activity [121].

Other small molecules with affinity for the mitochondria include sulfonylureas, anthracyclines, benzodiazepines, resveratrol, and porphyrin-based compounds [122]. However, as these agents have not been used for their targeting/delivery of a secondary agent to the mitochondria, they will not be discussed further here.

\section{Peptide-based agents}




\subsection{Mitochondria penetrating peptides}

Mitochondria penetrating peptides (MPPs) have some of the characteristics of DLCs; the peptides maintain a positive charge needed for charge-specific mitochondria uptake but also have hydrophobic residues that allow for penetration of the hydrophobic inner mitochondrial membrane [123]. These peptides are similar to CPPs (cell penetrating peptides), but as the IMM is more lipophilic than the plasma membrane, MPPs must be more lipophilic than their CPP counterparts [123]. These 4-16 amino acid peptides are made up of cationic (lysine and Darginine $=r$ ) and hydrophobic (phenylalanine and cyclohexylalanine $=\mathrm{Fx}$ ) residues. Further research into MPPs has elucidated the importance of length, hydrophobicity, and charge as they pertain to cell permeation, mitochondria-penetration and mitochondrial toxicity. While beyond the scope of this review, this detailed analysis can be found in elsewhere (see reference [124]). The overall conclusion of the study was that MPPs' mitochondrial penetration is driven by an electrochemical gradient (positively charged peptide and negatively charged mitochondria), and the majority of MPPs accumulate in the matrix [123, 124]. As the D-arginine residues contain the guanidinium functional group, these peptides are related to the small-molecule guanidiniumbased carriers discussed in section 4.2.

MPPs have been tested for their ability to deliver therapeutic agents to the mitochondria. The efficacy of cisplatin, a commonly used chemotherapeutic agent, is to some extent due to its damaging effects on mitochondrial DNA [125]. As the mitochondria of certain cisplatin-resistant cell lines are known to have increased mitochondrial membrane potential as well as reduced mitochondrial DNA damage upon treatment of the drug, researchers sought to find a way to deliver cisplatin more efficiently to the mitochondria. For that purpose, the researchers conjugated cisplatin to the nontoxic MPP $r(F x r)_{3}$ [125]. While nuclear DNA damage and cell cycle arrest (hallmarks of nuclear platinum activity) were not observed, mitochondrial accumulation of MPP-platinum and subsequent mitochondrial DNA damage were found equally in platinum-resistant and platinum-sensitive cell lines [125]. This work is proof-of-concept that MPPs can be used to deliver therapeutics preferentially, if not specifically, to mitochondria (either to the IMM or the matrix) [125], as shown in Fig. 1.

\subsection{Szeto-Schiller (SS) peptides}

Another class of mitochondrial targeting agents is the Szeto-Schiller (SS) peptides. These consist of alternating aromatic and basic amino acids [126]. Generally SS peptides are smaller than 10 amino acids and have a 3+ charge and a D amino acid in the first or second position [127]. As antioxidants, SS peptides target the inner mitochondrial membrane [78]. In situ SS peptides can reduce the ROS production, and consequently inhibit the mitochondrial permeability transition and cytochrome c release [78]. The antioxidant function of SS peptides is carried out by the tyrosine or dimethyltyrosine residue, which scavenge peroxynitrite and hydrogen peroxide and inhibit lipid oxidation, thus preventing oxidative cell death [127]. Their cellular uptake is energy independent [128], and SS peptides can freely penetrate the cells at physiological $\mathrm{pH}$, despite their +3 charge [126]. While the mechanism by which SS peptides target the mitochondria is unclear, it is thought that there is an electrostatic attraction between the cationic SS peptide with cardiolipin in the IMM. The two basic amino acids on the SS peptide are thought to interact with the phosphate head groups of cardiolipin. As a result, the aromatic residues are in proximity to 
the hydrophobic acyl chain region [40], and the SS peptides concentrate to greater levels in the IMM versus the matrix [78]. SS-02 (Dmt-D-Arg-Phe-Lys-NH2) is the prototype of the SS peptides [78]. The rearrangement of the first two amino acids leads to SS-31, a tetra-peptide which consists a D-Arg in first and a dimethyltyrosine in second position. SS-31 shows similar antioxidant activity as SS-02. Consequently the antioxidant properties of SS-peptides do not depend on the order of the four amino acids [78].

One major advantage of the SS peptides is that they can be taken up by depolarized mitochondria of diseased cells [78]. For this reason the SS peptides seem to be suitable as a delivery device for a variety of disease states [129]. SS peptides' favorable pharmacokinetic profile, high resistance to degradation, and small size (and resulting simplicity of synthesis), make them a promising candidate for targeting therapeutics to the mitochondria [126].

\subsection{XJB peptides}

The antibiotic Gramicidin S is a known disruptor of bacterial membranes, which is thought to be responsible for its efficacy as an antibiotic [130]. However, GS interacts more strongly with anionic membranes than zwitterionic membranes [130]. Due to the similarities of bacterial and mitochondrial membranes, pentapeptide derivatives of Gramicidin $\mathrm{S}$ have been used for targeting human mitochondria. One lead pentapeptide, XJB-5-131, with sequence Leu-D-Phe-Pro-ValOrn, was attached to ROS scavenger 4-AT [131]. XJB-5-131 was shown to deliver 4-AT to the mitochondria and subsequently prevent superoxide production in cells. This in turn protected cells against pro-apoptotic treatments including actinomycin $\mathrm{D}$, radiation, and staurosporine [122], both in vitro and in vivo [131]. Of particular interest, targeting of XJB-5-131 to the mitochondria does not depend of mitochondrial membrane potential; localization to the mitochondria is accomplished by insertion of the Leu-D-Phe-Pro-Val-Orn sequence into the inner mitochondrial membrane [132]. Therefore, XJB-5-131 and its analogues could be used to target damaged/diseased mitochondria. While 4-AT was attached in these studies, it may be possible to deliver other small molecules or peptides with these gramicidin $\mathrm{S}$ derivatives.

\subsection{Mitochondrial targeting sequences}

Although mitochondria can synthesize a small fraction of their own proteins, over $98 \%$ of the total mitochondrial proteins are synthesized from nuclear genes and then transported to the mitochondria [133]. In order to transport the proteins to their final site in or on the mitochondria, proteins make use of $\mathrm{N}$ - or C-terminal mitochondrial targeting sequences (MTSs).

Although no consensus sequence exists for MTSs, there are 2 general classes of MTSs: N-terminal presequences and tail-anchored sequences [67]. Proteins with tail-anchored MTSs generally are inserted into the OMM, although this mechanism is not fully understood. Most matrix and some intermembrane space proteins have a N-terminal presequence, usually a 20-40 amino acids in length [117]. These signals target the mitochondrial import machinery, namely the TOM and TIM complexes. After entering the inner membrane space via TOM, proteins can either be inserted into the inner membrane or continue on into the matrix or inner membrane by utilizing the TIM complex. A summary of the mitochondrial import machinery has been presented in section 2.3 and Fig. 2. For further details see the excellent review by Ahting and colleagues [71].

It will be clear to the readers then that, depending on the preferred target of the 
therapeutic, different MTSs can be utilized to target the OMM, IMS, and IMM. This is generally an underutilized fact that may have implications for improved cancer therapies. Table 1 has a sample of MTSs, their protein of origin, and site of insertion into the mitochondria $[66,112,113$, 134-137]. These and other MTSs and their localization in the mitochondria are shown in Fig. 1. Table 1. Select mitochondrial targeting sequences and their mitochondrial destination (insertion site)

\begin{tabular}{|l|l|l|l|l|}
\hline Name & Mitochondrial Targeting Sequence & Protein of Origin & $\begin{array}{l}\text { Insertion } \\
\text { Site }\end{array}$ & Ref. \\
\hline Bak & GNGPILNVLVVLGVVLLGQFVVRRFFKS & Bak & OMM & {$[113]$} \\
\hline Bax & GTPTWQTVTIFVAGVLTASLTIWKKMG & Bax & OMM & {$[113]$} \\
\hline TOM & MVGRNSAIAAGVCGALFIGYCIYFDRKRRSDPN & TOM20 & OMM & {$[112]$} \\
\hline XL & RKGQERFNRWFLTGMTVAGVVLLGSLFSRK & Bcl-XL & OMM & {$[112]$} \\
\hline CCO & MSVLTPLLLRGTGSARRLPVPRAKIHSL & $\begin{array}{l}\text { Cyt. C Oxidase } \\
\text { Subunit VIII }\end{array}$ & IMM & {$[112]$} \\
\hline Cox8 & MSVLTPLLLRSLTGSARRLMVPRAQV & Cox8 & IMM & {$[136$,} \\
\hline APE1 & HSLLPALCDSKIRSKALGSDHCPITLYLAL & APE1 & Matrix & {$[66]$} \\
\hline cMTS & APVLSDFPLLQFFTRISNIPTIKKFL & $\begin{array}{l}\text { Glutathione S- } \\
\text { Transferase 4A-4 }\end{array}$ & Matrix & {$[134$,} \\
\hline MnSOD & MLSRQRKPPPDGPYVEVVRTVLF & $\begin{array}{l}\text { Mn-Superoxide } \\
\text { Dismutase }\end{array}$ & Matrix & {$[66]$} \\
\hline OTC & $\begin{array}{l}\text { MLFNLRILLNNAAFRNGHN } \\
\text { FMVRNFRCGQPLQNKVQ }\end{array}$ & $\begin{array}{l}\text { Ornithine } \\
\text { Transcarbamylase }\end{array}$ & Matrix & {$[112]$} \\
\hline
\end{tabular}

One advantage of MTSs is that they are biocompatible, as they originate from our own endogenous mitochondrial protein targeting systems. Further, as seen in Table 1, cargo can be specifically targeted within the mitochondria to the OMM, IMM, or matrix. However, poor solubility and cell permeability limits the use of MTS for drug delivery [2]. Also, targeting of MTSs may be perturbed in cells with damaged/diseased mitochondria [68]. Finally, proteins delivered to the mitochondrial matrix by MTSs must be in an unfolded state, which will limit the efficacy of some protein therapeutics [68]. Despite this, Flier and colleagues were able to deliver peptide nucleic acids conjugated to a MTS to the mitochondria both in vitro and in vivo [138]. Work from our lab has focused on delivering the proapoptotic protein p53 to the mitochondria using a variety of MTSs [112, 113, 139], described in the next section.

\subsection{Protein transduction domains}

A protein can be conjugated to a protein transduction domain (PTD) peptide, also known as cell penetrating peptides (CPP). The PTD peptide targets the protein to the mitochondria via a unknown mechanism that is independent of the MTS TIM/TOM pathway [140]. The transduction of the PTD fused protein may be advantageous since it does not require the presence of a specific receptor and transporter [141]. The most well-known PTD is arguably the 11-amino acid PTD derived from HIV TAT protein. With 6 arginine and 2 lysine residues, this TAT PTD has been shown to effectively target the fusion protein to the mitochondria $[140,141]$. Most PTDs share this arginine and lysine rich feature, but it is still unclear if these PTDs use the same mechanism for their activity [142]. Apparently, each PTD has its own restriction on the size of protein. For example, a fusion protein with Ant PTD is limited to less than 100 amino 
acid residues, while TAT PTD and VP22 PTD are able to transduce large proteins of more than 1000 amino acids $[142,143]$. HIV TAT has been used in conjunction with a MTS from Bcl-XL to deliver the FNK protein. The PTD allows passage through the cell membrane, and then the MTS targets it to the mitochondria. This PTD fused protein was able to protect the cell against necrosis and apoptosis [144-147]. If the target cells have defective TOM/TIM proteins, the use of a PTD is preferred over a MTS (presumably the charged PTD crosses the mitochondrial membrane in a non-specific manner). However, there has been some concern about the effectiveness of the PTD alone as a single targeting moiety because of its non-specificity. The PTD may require further study and modification to improve its properties and potential toxicity profile [148]. The advantages and limitations of PTDs have been extensively reviewed [140, 148]. Furthermore, the combination of both a PTD and a MTS has been attempted before with promising results. Some typical examples are TAT-mMDH-GFP (TAT PTD with MTS from mitochondrial malate dehydrogenase) and MTS-ExoIII-TAT (TAT PTD with MTS from MnSOD) [149, 150].

\section{Targeting a protein encoded in a gene to the mitochondria}

This gene therapy approach involves cloning a DNA sequence that encodes mitochondrial targeting signals to the gene of interest. The resulting recombinant gene, once delivered to the cell, would be expressed as a protein, and the MTS would direct this protein to the mitochondria. MTSs rely on the mitochondrial import machinery for entry into the cell (as described in section 2.3). As for relevant proteins to be targeted to the mitochondria, the most widely studied of these is the tumor suppressor p53. While p53 is widely known as a nuclear transcription factor that induces apoptosis and cell cycle arrest among other functions [151, 152], it also has a direct apoptogenic effect at the mitochondria [37, 110, 153, 154].

Moll's group showed that a transfected gene encoding p53 and a mitochondrial targeting signal (MTS) could induce apoptosis of cancer cells [155-157]. Mitochondrial targeting signals used included those from the pro-survival protein Bcl-XL, from Bcl-2 (both target the OMM), and the leader sequence from ornithine transcarbamylase (OTC) which directs proteins to the matrix (Table 2). p53-OTC in animal models of lymphoma and colon cancer showed some apoptotic effect, but was not superior to wild-type p53 [155, 156], nor have they advanced to the clinic. Nevertheless, Moll's group is the pioneer in this area. Our laboratory further explored targeting of p53 to different mitochondrial compartments (Fig. 1) including the OMM using MTS sequences derived from Bcl-XL (with a slightly different sequence than Moll) and from TOM. We examined mitochondrial targeting of p53 to the IMM using the MTS from cytochrome c oxidase ( $\mathrm{CCO}$ ), and recapitulated the targeting to the inner matrix using OTC (Table 2). Critically, we found that the OTC sequence itself had mitochondrial toxicity, and was not specific for p53 [112]. In this study, p53 with Bcl-XL MTS showed a p53-specific mitochondrial effect (apoptosis) [112], and the DNA binding domain (DBD) of p53 attached to this MTS was sufficient to cause apoptosis [158]. In fact, the DBD-Bcl-XL MTS constructs induced higher levels of apoptosis in some cancer cell lines [158].

Next, our group explored a novel hypothesis that pro-apoptotic Bak and Bax can be directly activated by targeting p53 to the mitochondria using the MTSs from Bak and Bax themselves. Transfecting plasmids encoding p53-Bak MTS, p53-BaxMTS or just the DBD of p53 attached to either Bak or Bax MTS, resulted in robust apoptosis in a variety of cancer cell 
lines including breast (T47D), lung (H1373), ovarian (SKOV-3), and cervical (HeLa) cells (Table 2). Interestingly, the DBD-MTS constructs were able to induce the highest amounts of apoptosis (Table 2) [113]. This approach using DBD-MTS is being actively pursued in our laboratory for gene therapy in a syngeneic orthotopic ovarian cancer mouse model [159].

Lastly, proteins other than p53 (or p53 subdomains) have been sent to the mitochondria for cancer therapy. Our lab has taken advantage of the hyper-oxidative environment of cancer cells and a cryptic MTS (cMTS) that only transports cargo to the mitochondria under such conditions $[160,161]$. In particular, the cMTS from GSTA4-4 is activated by phosphorylation by PKA or PKC in a reactive oxygen species dependent manner. This cMTS only directs its (cytoplasmic) cargo to the mitochondria in cells (such as cancer cells) that have high levels of reactive oxygen species (stimulated by PKA/PKC). Indeed, attachment of this cMTS to c-Abl (an oncoprotein that has a purported role in inducing apoptosis at the mitochondria) led to cell death in cancer cells with high ROS [160]. In another example, the oncogenic Bcr-Abl protein was shown to cause apoptosis when directly targeted to the mitochondria with a canonical MTS targeting the matrix [161]. These results are summarized in Table 2.

Table 2. Examples of gene therapy to deliver proteins to the mitochondria (shading indicates where comparisons are made from a single paper or similar papers).

\begin{tabular}{|c|c|c|c|c|c|}
\hline $\begin{array}{l}\text { Name of } \\
\text { gene (gene } \\
\text { delivered) }\end{array}$ & $\begin{array}{l}\text { Mitochondrial } \\
\text { targeting signal } \\
\text { (derived from) }\end{array}$ & $\begin{array}{l}\text { Targeted } \\
\text { location }\end{array}$ & $\begin{array}{lr}\text { Cancer } & \text { model } \\
\text { system/cell } & \text { lines } \\
\text { tested } & \\
\end{array}$ & Results & Refs \\
\hline $\begin{array}{l}\text { p53CTM } \\
\text { (p53) }\end{array}$ & $\begin{array}{l}\text { Transmembrane } \\
\text { domain from Bcl-2 }\end{array}$ & $\begin{array}{l}\text { Outer } \\
\text { membrane }\end{array}$ & $\begin{array}{ll}\text { Mouse } & \text { lymphoma } \\
\text { model } & \end{array}$ & $\begin{array}{l}\text { Apoptotic effect on } \\
\text { primary cells but } \\
\text { less than Lp53wt }\end{array}$ & {$[156]$} \\
\hline $\begin{array}{l}\text { p53CTB } \\
\text { (p53) }\end{array}$ & $\begin{array}{l}\text { Transmembrane } \\
\text { domain from Bcl-XL* }\end{array}$ & $\begin{array}{l}\text { Outer } \\
\text { membrane }\end{array}$ & $\begin{array}{l}\text { Mouse lymphoma } \\
\text { model; mouse solid } \\
\text { human tumor xenograft } \\
\text { model of colon cancer }\end{array}$ & (weakest construct) & $\begin{array}{l}{[155,} \\
156]\end{array}$ \\
\hline $\begin{array}{l}\text { Lp53wt } \\
\text { (p53) }\end{array}$ & $\begin{array}{l}\text { Ornithine } \\
\text { transcarbamylase } \\
\text { mitochondrial import } \\
\text { leader sequence } \\
\text { (OTC) }\end{array}$ & $\begin{array}{l}\text { Import into } \\
\text { matrix }\end{array}$ & $\begin{array}{l}\text { Mouse lymphoma } \\
\text { model; mouse solid } \\
\text { human tumor xenograft } \\
\text { model of colon cancer }\end{array}$ & $\begin{array}{l}\text { Caused apoptosis in } \\
\text { primary cells and } \\
\text { was superior to CTM } \\
\text { and CTB in vivo in } \\
\text { lymphoma and colon } \\
\text { models }\end{array}$ & $\begin{array}{l}{[155,} \\
156]\end{array}$ \\
\hline $\begin{array}{l}\text { pEGFP-p53- } \\
\text { XL } \\
(p 53)\end{array}$ & $\begin{array}{lr}\text { Bcl-XL } & \text { (slightly } \\
\text { different sequence } \\
\text { from above*) }\end{array}$ & $\begin{array}{l}\text { Outer } \\
\text { membrane }\end{array}$ & $\begin{array}{l}\text { T47D and MCF-7 breast } \\
\text { cancer cells }\end{array}$ & $\begin{array}{l}\text { p53-specific } \\
\text { apoptotic effect } \\
\text { (rather than a } \\
\text { general } \\
\text { mitochondrial toxic } \\
\text { effect) }\end{array}$ & [112] \\
\hline $\begin{array}{l}\text { pTOM- } \\
\text { EGFP-p53 } \\
(p 53)\end{array}$ & $\begin{array}{l}\text { Translocase of the } \\
\text { outer membrane } \\
\text { (TOM) }\end{array}$ & $\begin{array}{l}\text { Outer } \\
\text { membrane }\end{array}$ & $\begin{array}{l}\text { T47D and MCF-7 breast } \\
\text { cancer cells }\end{array}$ & $\begin{array}{l}\text { General } \\
\text { mitochondrial toxicity }\end{array}$ & [112] \\
\hline $\begin{array}{l}\text { pCCO- } \\
\text { EGFP-p53 } \\
\text { (p53) }\end{array}$ & $\begin{array}{l}\text { Cytochrome } \\
\text { oxidase }(\mathrm{CCO})\end{array}$ & $\begin{array}{l}\text { Inner } \\
\text { membrane }\end{array}$ & $\begin{array}{l}\text { T47D and MCF-7 breast } \\
\text { cancer cells }\end{array}$ & $\begin{array}{l}\text { General } \\
\text { mitochondrial toxicity }\end{array}$ & [112] \\
\hline $\begin{array}{l}\text { pOTC- } \\
\text { EGFP-p53 } \\
\text { (p53) }\end{array}$ & OTC & $\begin{array}{l}\text { Import into } \\
\text { matrix }\end{array}$ & $\begin{array}{l}\text { T47D and MCF-7 breast } \\
\text { cancer cells }\end{array}$ & $\begin{array}{l}\text { General } \\
\text { mitochondrial toxicity }\end{array}$ & {$[112]$} \\
\hline $\begin{array}{l}\text { p53-XL } \\
\text { (p53) }\end{array}$ & 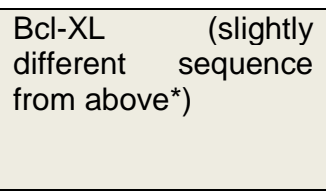 & $\begin{array}{l}\text { Outer } \\
\text { membrane }\end{array}$ & $\begin{array}{l}\text { T47D, MCF-7, MDA- } \\
\text { MB-231 breast cancer } \\
\text { cells; HeLa cervical } \\
\text { cells, and H1373 lung } \\
\text { cancer cells }\end{array}$ & $\begin{array}{l}\text { Apoptotic activity in } \\
\text { some cell lines but } \\
\text { less potent than } \\
\text { pDBD-XL }\end{array}$ & {$[158]$} \\
\hline $\begin{array}{l}\text { pDBD-XL } \\
\text { (DNA binding }\end{array}$ & $\begin{array}{lr}\text { Bcl-XL } & \text { (slightly } \\
\text { different } & \text { sequence }\end{array}$ & $\begin{array}{l}\text { Outer } \\
\text { membrane }\end{array}$ & 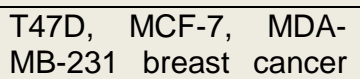 & $\begin{array}{l}\text { Caused highest } \\
\text { amount of apoptosis }\end{array}$ & {$[158]$} \\
\hline
\end{tabular}




\begin{tabular}{|c|c|c|c|c|c|}
\hline $\begin{array}{l}\text { domain from } \\
\text { p53) }\end{array}$ & from above*) & & $\begin{array}{l}\text { cells; HeLa cervical } \\
\text { cells, and H1373 lung } \\
\text { cancer cells }\end{array}$ & in all cell lines tested & \\
\hline p53-BakMTS & $\begin{array}{l}\text { Bak (pro-apoptotic } \\
\text { Bcl-2 family member) }\end{array}$ & $\begin{array}{l}\text { Outer } \\
\text { membrane }\end{array}$ & $\begin{array}{l}\text { T47D breast cancer } \\
\text { cells, H1373 lung } \\
\text { cancer cells, SKOV-3 } \\
\text { ovarian cancer cells, } \\
\text { HeLa cervical cancer } \\
\text { cells }\end{array}$ & $\begin{array}{l}\text { Apoptosis in all cell } \\
\text { lines }\end{array}$ & [113] \\
\hline $\begin{array}{l}\text { pDBD- } \\
\text { BakMTS } \\
\text { (p53 DNA } \\
\text { binding } \\
\text { domain) }\end{array}$ & $\begin{array}{l}\text { Bak (pro-apoptotic } \\
\text { Bcl-2 family member) }\end{array}$ & $\begin{array}{l}\text { Outer } \\
\text { membrane }\end{array}$ & $\begin{array}{llr}\text { T47D } & \text { breast } & \text { cancer } \\
\text { cells, } & \text { H1373 lung } \\
\text { cancer cells, SKOV-3 } \\
\text { ovarian cancer cells, } \\
\text { HeLa cervical cancer } \\
\text { cells }\end{array}$ & $\begin{array}{l}\text { Highest apoptosis in } \\
\text { all cell lines } \\
\text { compared to all } \\
\text { other constructs }\end{array}$ & {$[113]$} \\
\hline p53-BaxMTS & $\begin{array}{l}\text { Bax (pro-apoptotic } \\
\text { Bcl-2 family member) }\end{array}$ & $\begin{array}{l}\text { Outer } \\
\text { membrane }\end{array}$ & $\begin{array}{l}\text { T47D breast } \text { cancer } \\
\text { cells, H1373 lung } \\
\text { cancer cells, SKOV-3 } \\
\text { ovarian cancer cells, } \\
\text { HeLa cervical cancer } \\
\text { cells }\end{array}$ & $\begin{array}{l}\text { High apoptosis in } \\
\text { T47D and SKOV-3 } \\
\text { cells }\end{array}$ & [113] \\
\hline $\begin{array}{l}\text { pDBD- } \\
\text { BaxMTS } \\
\text { (p53 DNA } \\
\text { binding } \\
\text { domain) }\end{array}$ & $\begin{array}{l}\text { Bax (pro-apoptotic } \\
\text { Bcl-2 family member) }\end{array}$ & $\begin{array}{l}\text { Outer } \\
\text { membrane }\end{array}$ & $\begin{array}{llr}\text { T47D } & \text { breast } & \text { cancer } \\
\text { cells, } & \text { H1373 lung } \\
\text { cancer cells, SKOV-3 } \\
\text { ovarian cancer cells, } \\
\text { HeLa cervical cancer } \\
\text { cells }\end{array}$ & $\begin{array}{l}\text { Similar results as } \\
\text { pDBD-BakMTS } \\
\text { (high apoptosis) }\end{array}$ & {$[113]$} \\
\hline $\begin{array}{l}\text { pAbl-EGFP- } \\
\text { cMTS } \\
\text { (c-Abl) }\end{array}$ & $\begin{array}{l}\text { Cryptic MTS (cMTS) } \\
\text { from } \text { GSTA4-4; } \\
\text { activated } \\
\text { phosphorylation by } \\
\text { PKA or PKC in a } \\
\text { ROS dependent } \\
\text { manner }\end{array}$ & $\begin{array}{l}\text { Import into } \\
\text { matrix }\end{array}$ & $\begin{array}{l}\text { K562 leukemia cells, } \\
1471.1 \text { breast cancer } \\
\text { cells }\end{array}$ & Apoptotic effect & {$[160]$} \\
\hline $\begin{array}{l}\text { pBcr-Abl- } \\
\text { IMM }\end{array}$ & OTC & Matrix & K562 leukemia cells & $\begin{array}{l}\text { Apoptotic effect on } \\
\text { K562 leukemic cells }\end{array}$ & {$[161]$} \\
\hline
\end{tabular}

The advantages of using gene therapy vectors with encoded MTSs include the fact that recombinant DNA can easily be cloned, and the cell's own machinery translates this DNA to protein which targets the mitochondria via the MTS. Another advantage is that no chemical synthesis is required to make these constructs. On the other hand, the disadvantages of this method lie within the inherent issues of gene delivery. However, much work is being conducted in gene delivery, including viral $[162,163]$ and non-viral polymeric delivery techniques [164166]. Newer gene delivery concepts involve hybrid viral-polymer delivery systems pioneered by Yun, Kim, and colleagues [167, 168]. Many clinical trials for gene therapy exist $[169,170]$ and the first gene therapy approval in Europe occurred in 2012 for the drug Glybera for lipoprotein lipase deficiency [171]. Forthcoming advances in gene delivery will facilitate the successful use of these vectors for mitochondrially toxic cancer therapy.

\section{Cargo in polymers/nanoparticles/viruses targeted to the mitochondria}

These approaches use a polymeric complex, nanoparticle, or virus attached to a mitochondriotropic agent, and exploit unique mitochondrial characteristics which direct their targeting. The unique characteristics include its membrane potential, the mitochondrial fusion process, and the mitochondrial import machinery which recognizes MTSs [172]. 


\section{Exploiting high membrane potential of the mitochondria for delivery of cargo in polymers or nanoparticles}

Prototypical triphenylphosphonium (TPP) has been commonly used as a mitochondriotropic agent to target cargo-carrying polymers to the mitochondria. As mentioned in section 4.1, charged cationic TPP molecules take advantage of the high membrane potential in the mitochondrial inner membrane, and preferentially accumulate at the mitochondrial matrix, which is negatively charged [173].

Kopeček et al. have attached TPP to HPMA ( $N$-(2-hydroxylpropyl)methacrylamide) nanoparticles synthesized with mesochlorin e6 (a photosensitizer). These TPP nanoparticles not only targeted the mitochondria, but caused increased ovarian cancer cell death upon light activation compared to non-targeted controls [174]. TPP in the form of steryltriphenylphosphonium (STPP) has also been incorporated into liposomes encapsulating the apoptogenic ceramide sphingolipid [175]. This resulted in mitochondrial accumulation of the liposomes, and improvement in the efficacy of ceramide. Similarly, paclitaxel was encapsulated in STPP liposomes, resulting in mitochondrial accumulation of paclitaxel and improved cell killing in ovarian cancer cells. Finally, Patel et al. incorporated the diterpene drug sclareol in STPP liposomes, and found efficacy against colon cancer and leukemia cells. TPP has also been used in PEG-PE modified liposomes to deliver paclitaxel to the mitochondria [176], with efficacy in both breast cancer cells and a mouse model. Likewise, Dhar et al. have conjugated poly(lactic-co-glycolic acid) (PLGA) and polyethylene glycol (PEG) copolymer to a TPP cation, which is known to enter the mitochondrial matrix. These polymeric complexes can accommodate various drugs in their hydrophobic interiors. The first application of this technology was for atherosclerotic disease [177] but has been tested in cervical cancer cells [177], and has further applications in other cancers [178]. Dhar's group has also noted an optimal nanoparticle size of 80-100nm for effective delivery to the mitochondria [177]. Lastly, the dicationic compound dequalinium is similarly charged as TPP, and can self-assemble into liposomes (DQAsomes) to deliver paclitaxel to the mitochondria of colon cancer cells [179] as well.

In addition to their conceptually simple/ elegant design, the advantages of using TPP or TPP-like compounds as a carrier for nanoparticles include the ability to either conjugate TPP directly to the polymer or modify TPP (STPP) and incorporate into liposomes. Disadvantages include the need for chemical synthesis, and general toxicity, since there is no specificity for cancer cell mitochondria. One approach to overcome this used folate to target cancer cells (which have folate receptors on their surface) in combination with STPP targeting to the mitochondria. This approach used folic acid-PEG-cholesterol/STPP liposomes that encapsulated the drug doxorubicin (a redox recycling drug that increases ROS) [180]. In KB cells (oral carcinoma cells), these multifunctionalized and fairly complex liposomes showed high accumulation, mitochondrial targeting, and increased ROS (and subsequently, high apoptosis). They were not, however, tested in other cell lines [180].

\section{Utilizing the mitochondrial fusion process for delivery of cargo in polymers/nanoparticles}

It is well-known that "fusion of mitochondria serves to mix and unify mitochondrial compartments" for genomic maintenance [181]. Identification of liposomes (with varying lipid composition and/or containing fusogenic peptides) that can fuse with mitochondria could be used 
to deliver cargo to mitochondria. Yamada et al. designed a liposomal carrier (MITO-Porter) that carries octaarginine (R8) charged moieties on the surface. These MITO-Porter liposomes were found to internalize by micropinocytosis, and bind to and fuse to mitochondria (via electrostatic interactions). While no cancer therapeutic was delivered, GFP (green fluorescent protein) was delivered as model cargo since it is easily detected by fluorescence [182]. Further, Harashima et al. were the first to show genome targeting of an antisense RNA with MITO-Porter, which impacted mitochondrial function [183]. This group also showed delivery of DNase I into the mitochondria with a version of MITO-Porter, demonstrating its potential as a therapy selective for the mitochondrial genome [182]. Additionally, transferrin modified liposomes have incorporated fusogenic peptides (GALA peptide) for fusion of these liposomes with mitochondria. These liposomes contained mastoparan (a drug that induces mitochondrial permeability transition to cause apoptosis). Transferrin was used as a targeting agent for cancer cells that have transferrin receptor upregulated on their surface. This system successfully demonstrated cytochrome c release (a marker for apoptosis) in K562 human leukemia cells [184]. Utilizing the mitochondrial fusion process for drug delivery appears to be more complicated than other strategies mentioned here; it could be due to the difficulty in selective fusion to mitochondria (vs. the cell membrane). Besides work by Yamada and colleagues, there are limited reports in this area.

\section{Utilizing mitochondrial targeting sequences (MTSs) for delivery of cargo in polymers/nanoparticles or adenovirus}

Mitochondrial targeting peptide signals, like mitochondriotropic cationic compounds (TPP), can be used to deliver polymers with cargo to the mitochondria. MTSs rely on the mitochondrial import machinery for import into the cell $[185,186]$. This includes the TOM complex for import across the outer mitochondrial membrane and the TIM complex if destined for the inner mitochondrial membrane as mentioned in section 2.3 and Fig. 2.

If targeted to the mitochondrial, photoactive gold nanoparticles could induce extrinsic apoptosis [136]. Therefore, the effects of gold nanoparticles have been tested for their use in cancer therapy in the presence of photothermal energy. Glycosylated dendrimers were used to transfect gold nanoparticles conjugated to GFP with the MTS from Cox8 (targets the inner membrane of the mitochondria) [136]. In this rather complicated system, apoptosis of breast cancer cells was achieved. Also, gene delivery to the mitochondria was achieved by modifying an adenoviral vector with the MTS from Cox 8 again [187]. The adenoviral vector was modified so that the VP2 capsid protein would express the MTS, and direct it to the mitochondria. While not a cancer application, this approach delivered the ND4 gene (under the control of a mitochondrial promoter), the mutation of which is implicated in Leber's optical neuropathy, to the mitochondria. This resulted in prevention of visual loss in an animal model [187], and is a highly promising strategy for gene therapy of mitochondrial diseases.

The main disadvantages of using MTSs to deliver polymers/nanoparticles are the complexity of the systems, and the size limitation for import to the mitochondria. While MTSs can import proteins easily, the size of polymeric delivery systems or nanoparticles will have to be optimized for maximal delivery to the mitochondria. It is thought that the diameter of the active translocon into the mitochondria is between 40-60 A [188]. However, the example using a MTS to deliver an adenovirus shows promise, and if size obstacles can be overcome, polymer/nanoparticle delivery by MTSs may be similarly successful. 
Fig. 3 summarizes the strategies in this paper for directing drugs and macromolecules to the mitochondria. Specific sub-compartmentalization of mitochondrial localization of these strategies (if known) is summarized in Fig. 1.

\section{Perspectives}

In the last decade, there has been great interest in targeting drugs and macromolecules to the mitochondria for treatment of cancers. A potential issue with mitochondrial targeting for cancer is the general toxicity to all cells, not just cancer cells. Strategies to overcome this issue include first targeting cancer cells (with liposomes decorated with cancer-specific moieties such as folate) [180] or utilizing cancer specific promoters for expression of genes only in cancer cells. In other cases, targeting drugs to the mitochondria may uncover new mechanisms of drug action [174] or increased mitochondrial toxicity of old drugs (such as cisplatin) [125]. Our lab has also shown that tumor suppressor proteins like p53 can be reengineered and targeted to the mitochondria to increase their mitochondriolytic activity [112, 113, 139].

One of the main goals of this review is to make note of the potential opportunities for specific mitochondrial compartment localization (OMM, IMS, IMM, matrix), which may lead to improvements in mitochondrial therapeutics. For example, work in our lab has shown that sending p53 to the outer membrane of the mitochondria (rather than the IMS or matrix) shows superior apoptotic activity that is p53-specific (rather than due to general toxicity from plugging up the mitochondria) $[112,113,139]$. In other cases, delivering a gene ultimately to the matrix may be essential for the treatment of a disease that occurs due to a defect in a gene that gets transcribed inside the mitochondrial itself [187].

The concept of intramitochondrial trafficking has been proposed by Yamada et al. to describe the challenge of targeting drugs to a specific compartment of mitochondria for maximized efficacy [140]. For small molecules drugs or proteins that aim to induce apoptosis or necrosis, the destination should be the outer mitochondrial membrane (OMM), where most mitochondrial apoptotic factors reside. If the targets of the therapy are the proteins of the electron transport chain [140] or their coenzymes, the drugs should be delivered to the intermembrane space and the inner mitochondrial membrane [140]. Small interfering RNA (siRNA against mtDNA should be delivered to the mitochondrial matrix [183]. Using octoarginine (R8) as the sole carrier for delivery may result in cell penetration but only non-specific mitochondrial targeting. Notably, the D-arm of the tRNA Tyr has been reported to have a matrix import signal and has been used successfully to deliver siRNA into the mitochondrial matrix $[183,189,190]$. On the other hand, mitochondrial targeting signals may be advantageous over arginine-rich peptides in terms of the location specificity. Depending on the MTS signal, the cargo can be delivered to a specific site of the mitochondria [60]. In terms of intramitochondrial trafficking, there are many proteins that are responsible for the trafficking of substances inside mitochondria. One example is Ups1, which facilitates the transport of phospholipids between mitochondrial membranes [191]. The possibility of utilizing these proteins for intramitochondrial trafficking of drugs still requires further investigation.

Although not reviewed here, another area of active pursuit involves discovery of drugs that block anti-apoptotic proteins or enhance apoptotic proteins at the mitochondria. Improvement in the protein specificity of the drug (eg, minimize pan-inhibition), along with enhanced cancer targeting and mitochondrial compartment specificity may mitigate non-specific side effects that limit the use of current agents such as navitoclax (ABT-263). Navitoclax has 
dose-limiting side effects including thrombocytopenia, platelet toxicity, and T-cell lymphopenia $[192,193]$. We believe that the current improved understanding of the mitochondrial import process, and discovery of more MTSs combined with advanced drug delivery strategies, now provides the ability to target drug cargo to specific mitochondrial compartments. This is a currently under-explored area that is prime for new discoveries in cancer therapeutics.

\section{Acknowledgements}

Funding from NIH CA-151847 and DOD USAMRMC OC140231 are acknowledged. We would also like to acknowledge other scientific colleagues in this field whose works were not cited in this review due to space limitations.

\section{References}

[1] D. Park, P.J. Dilda, Mitochondria as targets in angiogenesis inhibition, Mol Aspects Med, 31 (2010) 113-131.

[2] S. Fulda, L. Galluzzi, G. Kroemer, Targeting mitochondria for cancer therapy, Nat Rev Drug Discov, 9 (2010) 447-464.

[3] I.R. Indran, G. Tufo, S. Pervaiz, C. Brenner, Recent advances in apoptosis, mitochondria and drug resistance in cancer cells, Biochim Biophys Acta, 1807 (2011) 735-745.

[4] S.J. Ralph, S. Rodriguez-Enriquez, J. Neuzil, E. Saavedra, R. Moreno-Sanchez, The causes of cancer revisited: "mitochondrial malignancy" and ROS-induced oncogenic transformation - why mitochondria are targets for cancer therapy, Mol Aspects Med, 31 (2010) 145-170.

[5] A.J. Souers, J.D. Leverson, E.R. Boghaert, S.L. Ackler, N.D. Catron, J. Chen, B.D. Dayton, H. Ding, S.H. Enschede, W.J. Fairbrother, D.C. Huang, S.G. Hymowitz, S. Jin, S.L. Khaw, P.J. Kovar, L.T. Lam, J. Lee, H.L. Maecker, K.C. Marsh, K.D. Mason, M.J. Mitten, P.M. Nimmer, A. Oleksijew, C.H. Park, C.M. Park, D.C. Phillips, A.W. Roberts, D. Sampath, J.F. Seymour, M.L. Smith, G.M. Sullivan, S.K. Tahir, C. Tse, M.D. Wendt, Y. Xiao, J.C. Xue, H. Zhang, R.A. Humerickhouse, S.H. Rosenberg, S.W. Elmore, ABT-199, a potent and selective BCL-2 inhibitor, achieves antitumor activity while sparing platelets, Nat Med, 19 (2013) 202-208.

[6] J.H. Hung, Y.N. Teng, L.H. Wang, I.J. Su, C.C. Wang, W. Huang, K.H. Lee, K.Y. Lu, L.H. Wang, Induction of $\mathrm{Bcl}-2$ expression by hepatitis B virus pre-S2 mutant large surface protein resistance to 5-fluorouracil treatment in Huh-7 cells, PLoS One, 6 (2011) e28977.

[7] J.I. Leu, P. Dumont, M. Hafey, M.E. Murphy, D.L. George, Mitochondrial p53 activates Bak and causes disruption of a Bak-Mcl1 complex, Nat Cell Biol, 6 (2004) 443-450.

[8] E.P. Holinger, T. Chittenden, R.J. Lutz, Bak BH3 peptides antagonize Bcl-xL function and induce apoptosis through cytochrome c-independent activation of caspases, J Biol Chem, 274 (1999) 13298-13304.

[9] J.E. Constance, C.S. Lim, Targeting malignant mitochondria with therapeutic peptides, Ther Deliv, 3 (2012) 961-979.

[10] M. Zick, R. Rabl, A.S. Reichert, Cristae formation-linking ultrastructure and function of mitochondria, Biochim Biophys Acta, 1793 (2009) 5-19.

[11] D.D. Newmeyer, S. Ferguson-Miller, Mitochondria: releasing power for life and unleashing the machineries of death, Cell, 112 (2003) 481-490. 
[12] D.C. Chan, Mitochondria: dynamic organelles in disease, aging, and development, Cell, 125 (2006) 1241-1252.

[13] S. Papa, P.L. Martino, G. Capitanio, A. Gaballo, D. De Rasmo, A. Signorile, V. Petruzzella, The oxidative phosphorylation system in mammalian mitochondria, Adv Exp Med Biol, 942 (2012) 337.

[14] J. Smeitink, L. van den Heuvel, S. DiMauro, The genetics and pathology of oxidative phosphorylation, Nat Rev Genet, 2 (2001) 342-352.

[15] D. Serra, P. Mera, M.I. Malandrino, J.F. Mir, L. Herrero, Mitochondrial fatty acid oxidation in obesity, Antioxid Redox Signal, 19 (2013) 269-284.

[16] J.D. McGarry, N.F. Brown, The mitochondrial carnitine palmitoyltransferase system. From concept to molecular analysis, Eur J Biochem, 244 (1997) 1-14.

[17] R. McFarland, R.W. Taylor, D.M. Turnbull, Mitochondrial disease--its impact, etiology, and pathology, Curr Top Dev Biol, 77 (2007) 113-155.

[18] R.W. Taylor, D.M. Turnbull, Mitochondrial DNA mutations in human disease, Nat Rev Genet, 6 (2005) 389-402.

[19] N.G. Larsson, J. Wang, H. Wilhelmsson, A. Oldfors, P. Rustin, M. Lewandoski, G.S. Barsh, D.A. Clayton, Mitochondrial transcription factor $A$ is necessary for mtDNA maintenance and embryogenesis in mice, Nat Genet, 18 (1998) 231-236.

[20] L.J. Wong, Recognition of mitochondrial DNA deletion syndrome with non-neuromuscular multisystemic manifestation, Genet Med, 3 (2001) 399-404.

[21] D.C. Chan, Mitochondrial fusion and fission in mammals, Annu Rev Cell Dev Biol, 22 (2006) 79-99.

[22] H.M. McBride, M. Neuspiel, S. Wasiak, Mitochondria: more than just a powerhouse, Curr Biol, 16 (2006) R551-560.

[23] A.M. van der Bliek, Q. Shen, S. Kawajiri, Mechanisms of mitochondrial fission and fusion, Cold Spring Harb Perspect Biol, 5 (2013).

[24] R.J. Youle, A.M. van der Bliek, Mitochondrial fission, fusion, and stress, Science, 337 (2012) 1062-1065.

[25] S.Y. Proskuryakov, A.G. Konoplyannikov, V.L. Gabai, Necrosis: a specific form of programmed cell death?, Exp Cell Res, 283 (2003) 1-16.

[26] A. Degterev, Z. Huang, M. Boyce, Y. Li, P. Jagtap, N. Mizushima, G.D. Cuny, T.J. Mitchison, M.A. Moskowitz, J. Yuan, Chemical inhibitor of nonapoptotic cell death with therapeutic potential for ischemic brain injury, Nat Chem Biol, 1 (2005) 112-119.

[27] W. Declercq, T. Vanden Berghe, P. Vandenabeele, RIP kinases at the crossroads of cell death and survival, Cell, 138 (2009) 229-232.

[28] J.M. Murphy, P.E. Czabotar, J.M. Hildebrand, I.S. Lucet, J.G. Zhang, S. Alvarez-Diaz, R. Lewis, N. Lalaoui, D. Metcalf, A.I. Webb, S.N. Young, L.N. Varghese, G.M. Tannahill, E.C. Hatchell, I.J.

Majewski, T. Okamoto, R.C. Dobson, D.J. Hilton, J.J. Babon, N.A. Nicola, A. Strasser, J. Silke, W.S. Alexander, The pseudokinase MLKL mediates necroptosis via a molecular switch mechanism, Immunity, 39 (2013) 443-453.

[29] Z. Wang, H. Jiang, S. Chen, F. Du, X. Wang, The mitochondrial phosphatase PGAM5 functions at the convergence point of multiple necrotic death pathways, Cell, 148 (2012) 228243. 
[30] A. Degterev, J. Hitomi, M. Germscheid, I.L. Ch'en, O. Korkina, X. Teng, D. Abbott, G.D. Cuny, C. Yuan, G. Wagner, S.M. Hedrick, S.A. Gerber, A. Lugovskoy, J. Yuan, Identification of RIP1 kinase as a specific cellular target of necrostatins, Nat Chem Biol, 4 (2008) 313-321.

[31] W. Zhou, J. Yuan, Necroptosis in health and diseases, Semin Cell Dev Biol, 35 (2014) 14-23.

[32] J.E. Chipuk, L. Bouchier-Hayes, D.R. Green, Mitochondrial outer membrane

permeabilization during apoptosis: the innocent bystander scenario, Cell Death Differ, 13 (2006) 1396-1402.

[33] D. Westphal, G. Dewson, P.E. Czabotar, R.M. Kluck, Molecular biology of Bax and Bak activation and action, Biochim Biophys Acta, 1813 (2011) 521-531.

[34] J.C. Martinou, R.J. Youle, Mitochondria in apoptosis: Bcl-2 family members and mitochondrial dynamics, Dev Cell, 21 (2011) 92-101.

[35] J. Wang, M.J. Lenardo, Roles of caspases in apoptosis, development, and cytokine maturation revealed by homozygous gene deficiencies, J Cell Sci, 113 ( Pt 5) (2000) 753-757.

[36] S. Kumar, Caspase function in programmed cell death, Cell Death Differ, 14 (2007) 32-43.

[37] J.E. Chipuk, T. Kuwana, L. Bouchier-Hayes, N.M. Droin, D.D. Newmeyer, M. Schuler, D.R.

Green, Direct activation of Bax by p53 mediates mitochondrial membrane permeabilization and apoptosis, Science, 303 (2004) 1010-1014.

[38] G. Dewson, T. Kratina, H.W. Sim, H. Puthalakath, J.M. Adams, P.M. Colman, R.M. Kluck, To trigger apoptosis, Bak exposes its $\mathrm{BH} 3$ domain and homodimerizes via $\mathrm{BH} 3$ :groove interactions, Mol Cell, 30 (2008) 369-380.

[39] S. Bleicken, O. Landeta, A. Landajuela, G. Basanez, A.J. Garcia-Saez, Proapoptotic Bax and Bak proteins form stable protein-permeable pores of tunable size, J Biol Chem, 288 (2013) 33241-33252.

[40] H.H. Szeto, First-in-class cardiolipin-protective compound as a therapeutic agent to restore mitochondrial bioenergetics, Br J Pharmacol, 171 (2014) 2029-2050.

[41] O. Landeta, A. Landajuela, D. Gil, S. Taneva, C. Di Primo, B. Sot, M. Valle, V.A. Frolov, G. Basanez, Reconstitution of proapoptotic BAK function in liposomes reveals a dual role for mitochondrial lipids in the BAK-driven membrane permeabilization process, J Biol Chem, 286 (2011) 8213-8230.

[42] T. Kuwana, M.R. Mackey, G. Perkins, M.H. Ellisman, M. Latterich, R. Schneiter, D.R. Green, D.D. Newmeyer, Bid, Bax, and lipids cooperate to form supramolecular openings in the outer mitochondrial membrane, Cell, 111 (2002) 331-342.

[43] J.J. Lum, D.E. Bauer, M. Kong, M.H. Harris, C. Li, T. Lindsten, C.B. Thompson, Growth factor regulation of autophagy and cell survival in the absence of apoptosis, Cell, 120 (2005) 237-248. [44] M.C. Wei, W.X. Zong, E.H. Cheng, T. Lindsten, V. Panoutsakopoulou, A.J. Ross, K.A. Roth, G.R. MacGregor, C.B. Thompson, S.J. Korsmeyer, Proapoptotic BAX and BAK: a requisite gateway to mitochondrial dysfunction and death, Science, 292 (2001) 727-730.

[45] E.H. Cheng, M.C. Wei, S. Weiler, R.A. Flavell, T.W. Mak, T. Lindsten, S.J. Korsmeyer, BCL-2, $\mathrm{BCL}-\mathrm{X}(\mathrm{L})$ sequester $\mathrm{BH} 3$ domain-only molecules preventing $\mathrm{BAX}$ - and $\mathrm{BAK}$-mediated mitochondrial apoptosis, Mol Cell, 8 (2001) 705-711.

[46] W.X. Zong, T. Lindsten, A.J. Ross, G.R. MacGregor, C.B. Thompson, BH3-only proteins that bind pro-survival Bcl-2 family members fail to induce apoptosis in the absence of Bax and Bak, Genes Dev, 15 (2001) 1481-1486. 
[47] C. Ploner, R. Kofler, A. Villunger, Noxa: at the tip of the balance between life and death, Oncogene, 27 Suppl 1 (2008) S84-92.

[48] D.C. Huang, A. Strasser, BH3-Only proteins-essential initiators of apoptotic cell death, Cell, 103 (2000) 839-842.

[49] L. Vela, O. Gonzalo, J. Naval, I. Marzo, Direct interaction of Bax and Bak proteins with Bcl-2 homology domain 3 (BH3)-only proteins in living cells revealed by fluorescence complementation, J Biol Chem, 288 (2013) 4935-4946.

[50] G. Kroemer, L. Galluzzi, C. Brenner, Mitochondrial membrane permeabilization in cell death, Physiol Rev, 87 (2007) 99-163.

[51] E.H. Cheng, T.V. Sheiko, J.K. Fisher, W.J. Craigen, S.J. Korsmeyer, VDAC2 inhibits BAK activation and mitochondrial apoptosis, Science, 301 (2003) 513-517.

[52] R.S. Whelan, K. Konstantinidis, A.C. Wei, Y. Chen, D.E. Reyna, S. Jha, Y. Yang, J.W. Calvert, T. Lindsten, C.B. Thompson, M.T. Crow, E. Gavathiotis, G.W. Dorn, 2nd, B. O'Rourke, R.N. Kitsis, Bax regulates primary necrosis through mitochondrial dynamics, Proc Natl Acad Sci U S A, 109 (2012) 6566-6571.

[53] I. Szabo, M. Soddemann, L. Leanza, M. Zoratti, E. Gulbins, Single-point mutations of a lysine residue change function of Bax and $\mathrm{BCl}-\mathrm{xL}$ expressed in Bax- and Bak-less mouse embryonic fibroblasts: novel insights into the molecular mechanisms of Bax-induced apoptosis, Cell Death Differ, 18 (2011) 427-438.

[54] L. Galluzzi, F. Pietrocola, J.M. Bravo-San Pedro, R.K. Amaravadi, E.H. Baehrecke, F. Cecconi, P. Codogno, J. Debnath, D.A. Gewirtz, V. Karantza, A. Kimmelman, S. Kumar, B. Levine, M.C. Maiuri, S.J. Martin, J. Penninger, M. Piacentini, D.C. Rubinsztein, H.U. Simon, A. Simonsen, A.M. Thorburn, G. Velasco, K.M. Ryan, G. Kroemer, Autophagy in malignant transformation and cancer progression, EMBO J, 34 (2015) 856-880.

[55] R.J. Youle, D.P. Narendra, Mechanisms of mitophagy, Nat Rev Mol Cell Biol, 12 (2011) 9-14. [56] R. Cesari, E.S. Martin, G.A. Calin, F. Pentimalli, R. Bichi, H. McAdams, F. Trapasso, A. Drusco, M. Shimizu, V. Masciullo, G. D'Andrilli, G. Scambia, M.C. Picchio, H. Alder, A.K. Godwin, C.M. Croce, Parkin, a gene implicated in autosomal recessive juvenile parkinsonism, is a candidate tumor suppressor gene on chromosome 6q25-q27, Proc Natl Acad Sci U S A, 100 (2003) 59565961.

[57] G. Poulogiannis, R.E. Mclntyre, M. Dimitriadi, J.R. Apps, C.H. Wilson, K. Ichimura, F. Luo, L.C. Cantley, A.H. Wyllie, D.J. Adams, M.J. Arends, PARK2 deletions occur frequently in sporadic colorectal cancer and accelerate adenoma development in Apc mutant mice, Proc Natl Acad Sci U S A, 107 (2010) 15145-15150.

[58] H. Wu, D. Xue, G. Chen, Z. Han, L. Huang, C. Zhu, X. Wang, H. Jin, J. Wang, Y. Zhu, L. Liu, Q. Chen, The BCL2L1 and PGAM5 axis defines hypoxia-induced receptor-mediated mitophagy, Autophagy, 10 (2014) 1712-1725.

[59] A.H. Chourasia, M.L. Boland, K.F. Macleod, Mitophagy and cancer, Cancer Metab, 3 (2015) 4.

[60] K. Okatsu, M. Kimura, T. Oka, K. Tanaka, N. Matsuda, Unconventional PINK1 localization to the outer membrane of depolarized mitochondria drives Parkin recruitment, J Cell Sci, 128 (2015) 964-978.

[61] E.M. Valente, P.M. Abou-Sleiman, V. Caputo, M.M. Muqit, K. Harvey, S. Gispert, Z. Ali, D. Del Turco, A.R. Bentivoglio, D.G. Healy, A. Albanese, R. Nussbaum, R. Gonzalez-Maldonado, T. 
Deller, S. Salvi, P. Cortelli, W.P. Gilks, D.S. Latchman, R.J. Harvey, B. Dallapiccola, G. Auburger, N.W. Wood, Hereditary early-onset Parkinson's disease caused by mutations in PINK1, Science, 304 (2004) 1158-1160.

[62] E. Schleiff, T. Becker, Common ground for protein translocation: access control for mitochondria and chloroplasts, Nat Rev Mol Cell Biol, 12 (2011) 48-59.

[63] W. Wickner, R. Schekman, Protein translocation across biological membranes, Science, 310 (2005) 1452-1456.

[64] D. Mokranjac, W. Neupert, Thirty years of protein translocation into mitochondria: unexpectedly complex and still puzzling, Biochim Biophys Acta, 1793 (2009) 33-41.

[65] C.M. Lee, J. Sedman, W. Neupert, R.A. Stuart, The DNA helicase, Hmi1p, is transported into mitochondria by a C-terminal cleavable targeting signal, J Biol Chem, 274 (1999) 20937-20942.

[66] M. Li, Z. Zhong, J. Zhu, D. Xiang, N. Dai, X. Cao, Y. Qing, Z. Yang, J. Xie, Z. Li, L. Baugh, G. Wang, D. Wang, Identification and characterization of mitochondrial targeting sequence of human apurinic/apyrimidinic endonuclease 1, J Biol Chem, 285 (2010) 14871-14881.

[67] C. Kemper, S.J. Habib, G. Engl, P. Heckmeyer, K.S. Dimmer, D. Rapaport, Integration of tailanchored proteins into the mitochondrial outer membrane does not require any known import components, J Cell Sci, 121 (2008) 1990-1998.

[68] W. Neupert, A perspective on transport of proteins into mitochondria: a myriad of open questions, Journal of molecular biology, 427 (2015) 1135-1158.

[69] G. von Heijne, Mitochondrial targeting sequences may form amphiphilic helices, EMBO J, 5 (1986) 1335-1342.

[70] T. Sollner, R. Pfaller, G. Griffiths, N. Pfanner, W. Neupert, A mitochondrial import receptor for the ADP/ATP carrier, Cell, 62 (1990) 107-115.

[71] A. Chacinska, C.M. Koehler, D. Milenkovic, T. Lithgow, N. Pfanner, Importing mitochondrial proteins: machineries and mechanisms, Cell, 138 (2009) 628-644.

[72] U. Ahting, M. Thieffry, H. Engelhardt, R. Hegerl, W. Neupert, S. Nussberger, Tom40, the pore-forming component of the protein-conducting TOM channel in the outer membrane of mitochondria, J Cell Biol, 153 (2001) 1151-1160.

[73] T. Saitoh, M. Igura, T. Obita, T. Ose, R. Kojima, K. Maenaka, T. Endo, D. Kohda, Tom20 recognizes mitochondrial presequences through dynamic equilibrium among multiple bound states, EMBO J, 26 (2007) 4777-4787.

[74] J.M. Herrmann, R. Kohl, Catch me if you can! Oxidative protein trapping in the intermembrane space of mitochondria, J Cell Biol, 176 (2007) 559-563.

[75] M. Mossalam, A.S. Dixon, C.S. Lim, Controlling subcellular delivery to optimize therapeutic effect, Ther Deliv, 1 (2010) 169-193.

[76] P. Rehling, K. Model, K. Brandner, P. Kovermann, A. Sickmann, H.E. Meyer, W. Kuhlbrandt, R. Wagner, K.N. Truscott, N. Pfanner, Protein insertion into the mitochondrial inner membrane by a twin-pore translocase, Science, 299 (2003) 1747-1751.

[77] M.P. Murphy, How mitochondria produce reactive oxygen species, Biochem J, 417 (2009) 1-13.

[78] K. Zhao, G.M. Zhao, D. Wu, Y. Soong, A.V. Birk, P.W. Schiller, H.H. Szeto, Cell-permeable peptide antioxidants targeted to inner mitochondrial membrane inhibit mitochondrial swelling, oxidative cell death, and reperfusion injury, J Biol Chem, 279 (2004) 34682-34690. 
[79] S.G. Rhee, Cell signaling. H2O2, a necessary evil for cell signaling, Science, 312 (2006) 18821883.

[80] I.R. Indran, M.P. Hande, S. Pervaiz, Tumor cell redox state and mitochondria at the center of the non-canonical activity of telomerase reverse transcriptase, Mol Aspects Med, 31 (2010) 21-28.

[81] I.R. Indran, M.P. Hande, S. Pervaiz, hTERT overexpression alleviates intracellular ROS production, improves mitochondrial function, and inhibits ROS-mediated apoptosis in cancer cells, Cancer Res, 71 (2011) 266-276.

[82] E. Pigeolet, P. Corbisier, A. Houbion, D. Lambert, C. Michiels, M. Raes, M.D. Zachary, J. Remacle, Glutathione peroxidase, superoxide dismutase, and catalase inactivation by peroxides and oxygen derived free radicals, Mech Ageing Dev, 51 (1990) 283-297.

[83] S. Raha, B.H. Robinson, Mitochondria, oxygen free radicals, disease and ageing, Trends Biochem Sci, 25 (2000) 502-508.

[84] M.P. Murphy, R.A. Smith, Targeting antioxidants to mitochondria by conjugation to lipophilic cations, Annu Rev Pharmacol Toxicol, 47 (2007) 629-656.

[85] M.P. Murphy, Targeting lipophilic cations to mitochondria, Biochim Biophys Acta, 1777 (2008) 1028-1031.

[86] M.S. Fliss, H. Usadel, O.L. Caballero, L. Wu, M.R. Buta, S.M. Eleff, J. Jen, D. Sidransky, Facile detection of mitochondrial DNA mutations in tumors and bodily fluids, Science, 287 (2000) 2017-2019.

[87] L. He, L. Luo, S.J. Proctor, P.G. Middleton, E.L. Blakely, R.W. Taylor, D.M. Turnbull, Somatic mitochondrial DNA mutations in adult-onset leukaemia, Leukemia, 17 (2003) 2487-2491.

[88] K. Polyak, Y. Li, H. Zhu, C. Lengauer, J.K. Willson, S.D. Markowitz, M.A. Trush, K.W. Kinzler, B. Vogelstein, Somatic mutations of the mitochondrial genome in human colorectal tumours, Nat Genet, 20 (1998) 291-293.

[89] V. Gogvadze, B. Zhivotovsky, S. Orrenius, The Warburg effect and mitochondrial stability in cancer cells, Mol Aspects Med, 31 (2010) 60-74.

[90] U.M. Moll, L.M. Schramm, p53--an acrobat in tumorigenesis, Crit Rev Oral Biol Med, 9 (1998) 23-37.

[91] R.O. Poyton, K.A. Ball, P.R. Castello, Mitochondrial generation of free radicals and hypoxic signaling, Trends Endocrinol Metab, 20 (2009) 332-340.

[92] N. Majewski, V. Nogueira, P. Bhaskar, P.E. Coy, J.E. Skeen, K. Gottlob, N.S. Chandel, C.B. Thompson, R.B. Robey, N. Hay, Hexokinase-mitochondria interaction mediated by Akt is required to inhibit apoptosis in the presence or absence of Bax and Bak, Mol Cell, 16 (2004) 819-830.

[93] J.C. Rathmell, C.J. Fox, D.R. Plas, P.S. Hammerman, R.M. Cinalli, C.B. Thompson, Aktdirected glucose metabolism can prevent Bax conformation change and promote growth factor-independent survival, Mol Cell Biol, 23 (2003) 7315-7328.

[94] L.C. Cantley, The phosphoinositide 3-kinase pathway, Science, 296 (2002) 1655-1657.

[95] A. Viale, P. Pettazzoni, C.A. Lyssiotis, H. Ying, N. Sanchez, M. Marchesini, A. Carugo, T.

Green, S. Seth, V. Giuliani, M. Kost-Alimova, F. Muller, S. Colla, L. Nezi, G. Genovese, A.K. Deem, A. Kapoor, W. Yao, E. Brunetto, Y. Kang, M. Yuan, J.M. Asara, Y.A. Wang, T.P. Heffernan, A.C. Kimmelman, H. Wang, J.B. Fleming, L.C. Cantley, R.A. DePinho, G.F. Draetta, Oncogene ablation- 
resistant pancreatic cancer cells depend on mitochondrial function, Nature, 514 (2014) 628632.

[96] E.D. Lagadinou, A. Sach, K. Callahan, R.M. Rossi, S.J. Neering, M. Minhajuddin, J.M. Ashton, S. Pei, V. Grose, K.M. O'Dwyer, J.L. Liesveld, P.S. Brookes, M.W. Becker, C.T. Jordan, BCL-2 inhibition targets oxidative phosphorylation and selectively eradicates quiescent human leukemia stem cells, Cell Stem Cell, 12 (2013) 329-341.

[97] I. Samudio, R. Harmancey, M. Fiegl, H. Kantarjian, M. Konopleva, B. Korchin, K. Kaluarachchi, W. Bornmann, S. Duvvuri, H. Taegtmeyer, M. Andreeff, Pharmacologic inhibition of fatty acid oxidation sensitizes human leukemia cells to apoptosis induction, J Clin Invest, 120 (2010) 142-156.

[98] T. Ni Chonghaile, K.A. Sarosiek, T.T. Vo, J.A. Ryan, A. Tammareddi, G. Moore Vdel, J. Deng, K.C. Anderson, P. Richardson, Y.T. Tai, C.S. Mitsiades, U.A. Matulonis, R. Drapkin, R. Stone, D.J. Deangelo, D.J. McConkey, S.E. Sallan, L. Silverman, M.S. Hirsch, D.R. Carrasco, A. Letai, Pretreatment mitochondrial priming correlates with clinical response to cytotoxic chemotherapy, Science, 334 (2011) 1129-1133.

[99] F.A. Sinicrope, R.L. Rego, K. Okumura, N.R. Foster, M.J. O'Connell, D.J. Sargent, H.E. Windschitl, Prognostic impact of bim, puma, and noxa expression in human colon carcinomas, Clin Cancer Res, 14 (2008) 5810-5818.

[100] P. Rochaix, S. Krajewski, J.C. Reed, F. Bonnet, J.J. Voigt, P. Brousset, In vivo patterns of Bcl2 family protein expression in breast carcinomas in relation to apoptosis, J Pathol, 187 (1999) 410-415. [101] C. Scaffidi, S. Fulda, A. Srinivasan, C. Friesen, F. Li, K.J. Tomaselli, K.M. Debatin, P.H. Krammer, M.E. Peter, Two CD95 (APO-1/Fas) signaling pathways, EMBO J, 17 (1998) 1675-1687. [102] T.J. McDonnell, P. Troncoso, S.M. Brisbay, C. Logothetis, L.W. Chung, J.T. Hsieh, S.M. Tu, M.L. Campbell, Expression of the protooncogene bcl-2 in the prostate and its association with emergence of androgen-independent prostate cancer, Cancer Res, 52 (1992) 6940-6944. [103] G.J. Berchem, M. Bosseler, L.Y. Sugars, H.J. Voeller, S. Zeitlin, E.P. Gelmann, Androgens induce resistance to bcl-2-mediated apoptosis in LNCaP prostate cancer cells, Cancer Res, 55 (1995) 735-738.

[104] K. Shigemasa, O. Katoh, Y. Shiroyama, S. Mihara, K. Mukai, N. Nagai, K. Ohama, Increased MCL-1 expression is associated with poor prognosis in ovarian carcinomas, Jpn J Cancer Res, 93 (2002) 542-550.

[105] J.E. Chipuk, T. Moldoveanu, F. Llambi, M.J. Parsons, D.R. Green, The BCL-2 family reunion, Mol Cell, 37 (2010) 299-310.

[106] M.F. van Delft, A.H. Wei, K.D. Mason, C.J. Vandenberg, L. Chen, P.E. Czabotar, S.N. Willis, C.L. Scott, C.L. Day, S. Cory, J.M. Adams, A.W. Roberts, D.C. Huang, The BH3 mimetic ABT-737 targets selective $\mathrm{Bcl}-2$ proteins and efficiently induces apoptosis via Bak/Bax if $\mathrm{Mcl}-1$ is neutralized, Cancer Cell, 10 (2006) 389-399.

[107] W.J. Placzek, J. Wei, S. Kitada, D. Zhai, J.C. Reed, M. Pellecchia, A survey of the antiapoptotic $\mathrm{Bcl}-2$ subfamily expression in cancer types provides a platform to predict the efficacy of Bcl-2 antagonists in cancer therapy, Cell Death Dis, 1 (2010) e40.

[108] S. Mazumder, G.S. Choudhary, S. Al-Harbi, A. Almasan, Mcl-1 Phosphorylation defines ABT-737 resistance that can be overcome by increased NOXA expression in leukemic B cells, Cancer Res, 72 (2012) 3069-3079. 
[109] P. Dumont, J.I. Leu, A.C. Della Pietra, 3rd, D.L. George, M. Murphy, The codon 72 polymorphic variants of p53 have markedly different apoptotic potential, Nat Genet, 33 (2003) 357-365.

[110] N.D. Marchenko, A. Zaika, U.M. Moll, Death signal-induced localization of p53 protein to mitochondria. A potential role in apoptotic signaling, J Biol Chem, 275 (2000) 16202-16212. [111] E.C. Pietsch, E. Perchiniak, A.A. Canutescu, G. Wang, R.L. Dunbrack, M.E. Murphy, Oligomerization of BAK by p53 utilizes conserved residues of the p53 DNA binding domain, $J$ Biol Chem, 283 (2008) 21294-21304.

[112] M. Mossalam, K.J. Matissek, A. Okal, J.E. Constance, C.S. Lim, Direct induction of apoptosis using an optimal mitochondrially targeted p53, Mol Pharm, 9 (2012) 1449-1458.

[113] K.J. Matissek, A. Okal, M. Mossalam, C.S. Lim, Delivery of a Monomeric p53 Subdomain with Mitochondrial Targeting Signals from Pro-Apoptotic Bak or Bax, Pharm Res, 31 (2014) 2503-2515.

[114] T.S. Wong, S. Rajagopalan, S.M. Freund, T.J. Rutherford, A. Andreeva, F.M. Townsley, M. Petrovich, A.R. Fersht, Biophysical characterizations of human mitochondrial transcription factor $A$ and its binding to tumor suppressor p53, Nucleic Acids Res, 37 (2009) 6765-6783. [115] R.A. Smith, R.C. Hartley, M.P. Murphy, Mitochondria-targeted small molecule therapeutics and probes, Antioxid Redox Signal, 15 (2011) 3021-3038.

[116] B.H. Honig, W.L. Hubbell, R.F. Flewelling, Electrostatic interactions in membranes and proteins, Annual review of biophysics and biophysical chemistry, 15 (1986) 163-193.

[117] J.S. Modica-Napolitano, J.R. Aprille, Delocalized lipophilic cations selectively target the mitochondria of carcinoma cells, Advanced drug delivery reviews, 49 (2001) 63-70.

[118] E.G. StanzI, B.M. Trantow, J.R. Vargas, P.A. Wender, Fifteen years of cell-penetrating, guanidinium-rich molecular transporters: basic science, research tools, and clinical applications, Accounts of chemical research, 46 (2013) 2944-2954.

[119] J. Fernandez-Carneado, M. Van Gool, V. Martos, S. Castel, P. Prados, J. de Mendoza, E. Giralt, Highly efficient, nonpeptidic oligoguanidinium vectors that selectively internalize into mitochondria, Journal of the American Chemical Society, 127 (2005) 869-874.

[120] J. Valero, M. Van Gool, R. Perez-Fernandez, P. Castreno, J. Sanchez-Quesada, P. Prados, J. de Mendoza, Non-peptidic cell-penetrating agents: synthesis of oligomeric chiral bicyclic guanidinium vectors, Organic \& biomolecular chemistry, 10 (2012) 5417-5430.

[121] B.H. Kang, J. Plescia, H.Y. Song, M. Meli, G. Colombo, K. Beebe, B. Scroggins, L. Neckers, D.C. Altieri, Combinatorial drug design targeting multiple cancer signaling networks controlled by mitochondrial Hsp90, J Clin Invest, 119 (2009) 454-464.

[122] A.T. Hoye, J.E. Davoren, P. Wipf, M.P. Fink, V.E. Kagan, Targeting mitochondria, Accounts of chemical research, 41 (2008) 87-97.

[123] K.L. Horton, K.M. Stewart, S.B. Fonseca, Q. Guo, S.O. Kelley, Mitochondria-penetrating peptides, Chemistry \& biology, 15 (2008) 375-382.

[124] K.L. Horton, M.P. Pereira, K.M. Stewart, S.B. Fonseca, S.O. Kelley, Tuning the activity of mitochondria-penetrating peptides for delivery or disruption, Chembiochem : a European journal of chemical biology, 13 (2012) 476-485.

[125] S.P. Wisnovsky, J.J. Wilson, R.J. Radford, M.P. Pereira, M.R. Chan, R.R. Laposa, S.J. Lippard, S.O. Kelley, Targeting mitochondrial DNA with a platinum-based anticancer agent, Chemistry \& biology, 20 (2013) 1323-1328. 
[126] H.H. Szeto, Cell-permeable, mitochondrial-targeted, peptide antioxidants, The AAPS journal, 8 (2006) E277-283.

[127] H.H. Szeto, Development of mitochondria-targeted aromatic-cationic peptides for neurodegenerative diseases, Annals of the New York Academy of Sciences, 1147 (2008) 112121.

[128] K. Zhao, G. Luo, G.M. Zhao, P.W. Schiller, H.H. Szeto, Transcellular transport of a highly polar 3+ net charge opioid tetrapeptide, The Journal of pharmacology and experimental therapeutics, 304 (2003) 425-432.

[129] J.S. Armstrong, Mitochondrial medicine: pharmacological targeting of mitochondria in disease, Br J Pharmacol, 151 (2007) 1154-1165.

[130] E.J. Prenner, M. Kiricsi, M. Jelokhani-Niaraki, R.N. Lewis, R.S. Hodges, R.N. McElhaney, Structure-activity relationships of diastereomeric lysine ring size analogs of the antimicrobial peptide gramicidin S: mechanism of action and discrimination between bacterial and animal cell membranes, J Biol Chem, 280 (2005) 2002-2011.

[131] Z. Xun, S. Rivera-Sanchez, S. Ayala-Pena, J. Lim, H. Budworth, E.M. Skoda, P.D. Robbins, L.J. Niedernhofer, P. Wipf, C.T. McMurray, Targeting of XJB-5-131 to mitochondria suppresses oxidative DNA damage and motor decline in a mouse model of Huntington's disease, Cell reports, 2 (2012) 1137-1142.

[132] M.P. Fink, C.A. Macias, J. Xiao, Y.Y. Tyurina, J. Jiang, N. Belikova, R.L. Delude, J.S. Greenberger, V.E. Kagan, P. Wipf, Hemigramicidin-TEMPO conjugates: novel mitochondriatargeted anti-oxidants, Biochemical pharmacology, 74 (2007) 801-809.

[133] M.T. Ryan, N.J. Hoogenraad, Mitochondrial-nuclear communications, Annual review of biochemistry, 76 (2007) 701-722.

[134] J.E. Constance, S.D. Despres, A. Nishida, C.S. Lim, Selective targeting of c-Abl via a cryptic mitochondrial targeting signal activated by cellular redox status in leukemic and breast cancer cells, Pharm Res, 29 (2012) 2317-2328.

[135] H. Raza, Dual localization of glutathione S-transferase in the cytosol and mitochondria: implications in oxidative stress, toxicity and disease, The FEBS journal, 278 (2011) 4243-4251. [136] M.M. Mkandawire, M. Lakatos, D.A. Springer, A. Clemens, D. Appelhans, U. KrauseBuchholz, W. Pompe, G. Rodel, M. Mkandawire, Induction of Apoptosis in Human Cancer Cells by Targeting Mitochondria with Gold Nanoparticles, Nanoscale, (2015).

[137] E. Perales-Clemente, P. Fernandez-Silva, R. Acin-Perez, A. Perez-Martos, J.A. Enriquez, Allotopic expression of mitochondrial-encoded genes in mammals: achieved goal, undemonstrated mechanism or impossible task?, Nucleic Acids Res, 39 (2011) 225-234. [138] A. Flierl, C. Jackson, B. Cottrell, D. Murdock, P. Seibel, D.C. Wallace, Targeted delivery of DNA to the mitochondrial compartment via import sequence-conjugated peptide nucleic acid, Molecular therapy : the journal of the American Society of Gene Therapy, 7 (2003) 550-557. [139] K.J. Matissek, M. Mossalam, A. Okal, C.S. Lim, The DNA binding domain of p53 is sufficient to trigger a potent apoptotic response at the mitochondria, Mol Pharm, 10 (2013) 3592-3602. [140] Y. Yamada, H. Akita, K. Kogure, H. Kamiya, H. Harashima, Mitochondrial drug delivery and mitochondrial disease therapy--an approach to liposome-based delivery targeted to mitochondria, Mitochondrion, 7 (2007) 63-71. 
[141] J. Embury, D. Klein, A. Pileggi, M. Ribeiro, S. Jayaraman, R.D. Molano, C. Fraker, N. Kenyon, C. Ricordi, L. Inverardi, R.L. Pastori, Proteins linked to a protein transduction domain efficiently transduce pancreatic islets, Diabetes, 50 (2001) 1706-1713.

[142] S.R. Schwarze, K.A. Hruska, S.F. Dowdy, Protein transduction: unrestricted delivery into all cells?, Trends Cell Biol, 10 (2000) 290-295.

[143] S. Fawell, J. Seery, Y. Daikh, C. Moore, L.L. Chen, B. Pepinsky, J. Barsoum, Tat-mediated delivery of heterologous proteins into cells, Proc Natl Acad Sci U S A, 91 (1994) 664-668.

[144] I.N. Shokolenko, M.F. Alexeyev, S.P. LeDoux, G.L. Wilson, The approaches for manipulating mitochondrial proteome, Environ Mol Mutagen, 51 (2010) 451-461.

[145] S. Asoh, I. Ohsawa, T. Mori, K. Katsura, T. Hiraide, Y. Katayama, M. Kimura, D. Ozaki, K. Yamagata, S. Ohta, Protection against ischemic brain injury by protein therapeutics, Proc Natl Acad Sci U S A, 99 (2002) 17107-17112.

[146] S. Asoh, T. Ohtsu, S. Ohta, The super anti-apoptotic factor Bcl-xFNK constructed by disturbing intramolecular polar interactions in rat Bcl-xL, J Biol Chem, 275 (2000) 37240-37245. [147] S. Asoh, T. Mori, S. Nagai, K. Yamagata, K. Nishimaki, Y. Miyato, Y. Shidara, S. Ohta, Zonal necrosis prevented by transduction of the artificial anti-death FNK protein, Cell Death Differ, 12 (2005) 384-394.

[148] A. Chauhan, A. Tikoo, A.K. Kapur, M. Singh, The taming of the cell penetrating domain of the HIV Tat: myths and realities, J Control Release, 117 (2007) 148-162.

[149] I.N. Shokolenko, M.F. Alexeyev, S.P. LeDoux, G.L. Wilson, TAT-mediated protein transduction and targeted delivery of fusion proteins into mitochondria of breast cancer cells, DNA Repair (Amst), 4 (2005) 511-518.

[150] V. Del Gaizo, R.M. Payne, A novel TAT-mitochondrial signal sequence fusion protein is processed, stays in mitochondria, and crosses the placenta, Mol Ther, 7 (2003) 720-730.

[151] K.H. Vousden, p53: death star, Cell, 103 (2000) 691-694.

[152] S. Reaz, M. Mossalam, A. Okal, C.S. Lim, A single mutant, A276S of p53, turns the switch to apoptosis, Mol Pharm, 10 (2013) 1350-1359.

[153] S. Erster, M. Mihara, R.H. Kim, O. Petrenko, U.M. Moll, In vivo mitochondrial p53 translocation triggers a rapid first wave of cell death in response to DNA damage that can precede p53 target gene activation, Mol Cell Biol, 24 (2004) 6728-6741.

[154] M. Mihara, S. Erster, A. Zaika, O. Petrenko, T. Chittenden, P. Pancoska, U.M. Moll, p53 has a direct apoptogenic role at the mitochondria, Mol Cell, 11 (2003) 577-590.

[155] G. Palacios, H.C. Crawford, A. Vaseva, U.M. Moll, Mitochondrially targeted wild-type p53 induces apoptosis in a solid human tumor xenograft model, Cell Cycle, 7 (2008) 2584-2590. [156] G. Palacios, U.M. Moll, Mitochondrially targeted wild-type p53 suppresses growth of mutant p53 lymphomas in vivo, Oncogene, 25 (2006) 6133-6139.

[157] F. Talos, O. Petrenko, P. Mena, U.M. Moll, Mitochondrially targeted p53 has tumor suppressor activities in vivo, Cancer Res, 65 (2005) 9971-9981.

[158] K.J. Matissek, M. Mossalam, A. Okal, C.S. Lim, The DNA binding domain of p53 is sufficient to trigger a potent apoptotic response at the mitochondria, Molecular Pharmaceutics, 10 (2013) 3592-3602.

[159] S. Cho, Y. Sun, A.P. Soisson, M.K. Dodson, C.M. Peterson, E.A. Jarboe, A.M. Kennedy, M.M. Janat-Amsbury, Characterization and Evaluation of Pre-clinical Suitability of a Syngeneic Orthotopic Mouse Ovarian Cancer Model, Anticancer Res, 33 (2013) 1317-1324. 
[160] J.E. Constance, S.D. Despres, A. Nishida, C.S. Lim, Selective targeting of c-Abl via a cryptic mitochondrial targeting signal activated by cellular redox status in leukemic and breast cancer cells, Pharmaceutical research, 29 (2012) 2317-2328.

[161] J.E. Constance, D.W. Woessner, K.J. Matissek, M. Mossalam, C.S. Lim, Enhanced and selective killing of chronic myelogenous leukemia cells with an engineered BCR-ABL binding protein and imatinib, Mol Pharm, 9 (2012) 3318-3329.

[162] R.G. Crystal, Adenovirus: the first effective in vivo gene delivery vector, Hum Gene Ther, 25 (2014) 3-11.

[163] N. Nayerossadat, T. Maedeh, P.A. Ali, Viral and nonviral delivery systems for gene delivery, Adv Biomed Res, 1 (2012) 27.

[164] D. Ibraheem, A. Elaissari, H. Fessi, Gene therapy and DNA delivery systems, Int J Pharm, 459 (2014) 70-83.

[165] D. Wang, G. Gao, State-of-the-art human gene therapy: part I. Gene delivery technologies, Discov Med, 18 (2014) 67-77.

[166] T. Zhang, Gene delivery for cancer therapy, Curr Drug Deliv, 11 (2014) 233-242.

[167] J. Kim, H.Y. Nam, J.W. Choi, C.O. Yun, S.W. Kim, Efficient lung orthotopic tumor-growth suppression of oncolytic adenovirus complexed with RGD-targeted bioreducible polymer, Gene Ther, 21 (2014) 476-483.

[168] J. Kim, H.Y. Nam, T.I. Kim, P.H. Kim, J. Ryu, C.O. Yun, S.W. Kim, Active targeting of RGDconjugated bioreducible polymer for delivery of oncolytic adenovirus expressing shRNA against IL-8 mRNA, Biomaterials, 32 (2011) 5158-5166.

[169] K.J. Matissek, R.R. Bender, J.R. Davis, C.S. Lim, Targets in Gene Therapy, in: Y. You (Ed.) Choosing Targets for Gene Therapy, InTech, 2011.

[170] S.L. Ginn, I.E. Alexander, M.L. Edelstein, M.R. Abedi, J. Wixon, Gene therapy clinical trials worldwide to 2012 - an update, J Gene Med, 15 (2013) 65-77.

[171] S. Yla-Herttuala, Endgame: Glybera Finally Recommended for Approval as the First Gene Therapy Drug in the European Union, Molecular therapy : the journal of the American Society of Gene Therapy, 20 (2012) 1831-1832.

[172] Targeted drug delivery: concepts and design, Anticancer Research, 35 (2015) 3111.

[173] M.P. Murphy, R.A. Smith, Targeting antioxidants to mitochondria by conjugation to lipophilic cations, Annu Rev Pharmacol Toxicol, 47 (2007) 629-656.

[174] V. Cuchelkar, P. Kopeckova, J. Kopecek, Novel HPMA copolymer-bound constructs for combined tumor and mitochondrial targeting, Molecular pharmaceutics, 5 (2008) 776-786.

[175] S.V. Boddapati, G.G.M. D'Souza, S. Erdogan, V.P. Torchilin, V. Weissig, Organelle-Targeted Nanocarriers: Specific Delivery of Liposomal Ceramide to Mitochondria Enhances Its Cytotoxicity in Vitro and in Vivo, Nano Letters, 8 (2008) 2559-2563.

[176] S. Biswas, N.S. Dodwadkar, P.P. Deshpande, V.P. Torchilin, Liposomes loaded with paclitaxel and modified with novel triphenylphosphonium-PEG-PE conjugate possess low toxicity, target mitochondria and demonstrate enhanced antitumor effects in vitro and in vivo, J Control Release, 159 (2012) 393-402.

[177] S. Marrache, S. Dhar, Biodegradable synthetic high-density lipoprotein nanoparticles for atherosclerosis, Proceedings of the National Academy of Sciences of the United States of America, 110 (2013) 9445-9450. 
[178] S. Marrache, R.K. Pathak, S. Dhar, Formulation and optimization of mitochondria-targeted polymeric nanoparticles, Methods Mol Biol, 1265 (2015) 103-112.

[179] V. Weissig, S.M. Cheng, G.G. D'Souza, Mitochondrial pharmaceutics, Mitochondrion, 3 (2004) 229-244.

[180] S.S. Malhi, A. Budhiraja, S. Arora, K.R. Chaudhari, K. Nepali, R. Kumar, H. Sohi, R.S. Murthy, Intracellular delivery of redox cycler-doxorubicin to the mitochondria of cancer cell by folate receptor targeted mitocancerotropic liposomes, Int J Pharm, 432 (2012) 63-74.

[181] B. Westermann, Merging mitochondria matters: cellular role and molecular machinery of mitochondrial fusion, EMBO Rep, 3 (2002) 527-531.

[182] Y. Yamada, H. Akita, H. Kamiya, K. Kogure, T. Yamamoto, Y. Shinohara, K. Yamashita, H. Kobayashi, H. Kikuchi, H. Harashima, MITO-Porter: A liposome-based carrier system for delivery of macromolecules into mitochondria via membrane fusion, Biochimica et Biophysica Acta, 1778 (2008) 423-432.

[183] R. Furukawa, Y. Yamada, E. Kawamura, H. Harashima, Mitochondrial delivery of antisense RNA by MITO-Porter results in mitochondrial RNA knockdown, and has a functional impact on mitochondria, Biomaterials, 57 (2015) 107-115.

[184] Y. Yamada, Y. Shinohara, T. Kakudo, S. Chaki, S. Futaki, H. Kamiya, H. Harashima, Mitochondrial delivery of mastoparan with transferrin liposomes equipped with a $\mathrm{pH}$-sensitive fusogenic peptide for selective cancer therapy, Int J Pharm, 303 (2005) 1-7.

[185] N. Pfanner, A. Geissler, Versatility of the mitochondrial protein import machinery, Nature reviews. Molecular cell biology, 2 (2001) 339-349.

[186] A.B. Harbauer, R.P. Zahedi, A. Sickmann, N. Pfanner, C. Meisinger, The protein import machinery of mitochondria-a regulatory hub in metabolism, stress, and disease, Cell Metab, 19 (2014) 357-372.

[187] H. Yu, R.D. Koilkonda, T.H. Chou, V. Porciatti, S.S. Ozdemir, V. Chiodo, S.L. Boye, S.E. Boye, W.W. Hauswirth, A.S. Lewin, J. Guy, Gene delivery to mitochondria by targeting modified adenoassociated virus suppresses Leber's hereditary optic neuropathy in a mouse model, Proceedings of the National Academy of Sciences of the United States of America, 109 (2012) E1238-1247.

[188] K.N. Truscott, K. Brandner, N. Pfanner, Mechanisms of protein import into mitochondria, Curr Biol, 13 (2003) R326-337.

[189] S. Mahapatra, S. Ghosh, S.K. Bera, T. Ghosh, A. Das, S. Adhya, The D arm of tRNATyr is necessary and sufficient for import into Leishmania mitochondria in vitro, Nucleic Acids Res, 26 (1998) 2037-2041.

[190] S.N. Bhattacharyya, S. Chatterjee, S. Adhya, Mitochondrial RNA import in Leishmania tropica: aptamers homologous to multiple tRNA domains that interact cooperatively or antagonistically at the inner membrane, Mol Cell Biol, 22 (2002) 4372-4382.

[191] M. Connerth, T. Tatsuta, M. Haag, T. Klecker, B. Westermann, T. Langer, Intramitochondrial transport of phosphatidic acid in yeast by a lipid transfer protein, Science, 338 (2012) 815-818.

[192] R.W. Rooswinkel, B. van de Kooij, M. Verheij, J. Borst, Bcl-2 is a better ABT-737 target than $\mathrm{Bcl}-\mathrm{xL}$ or $\mathrm{Bcl}-\mathrm{w}$ and only Noxa overcomes resistance mediated by $\mathrm{Mcl}-1, \mathrm{Bfl}-1$, or $\mathrm{Bcl}-\mathrm{B}$, Cell Death Dis, 3 (2012) e366. 
[193] W.H. Wilson, O.A. O'Connor, M.S. Czuczman, A.S. LaCasce, J.F. Gerecitano, J.P. Leonard, A. Tulpule, K. Dunleavy, H. Xiong, Y.L. Chiu, Y. Cui, T. Busman, S.W. Elmore, S.H. Rosenberg, A.P. Krivoshik, S.H. Enschede, R.A. Humerickhouse, Navitoclax, a targeted high-affinity inhibitor of BCL-2, in lymphoid malignancies: a phase 1 dose-escalation study of safety, pharmacokinetics, pharmacodynamics, and antitumour activity, Lancet Oncol, 11 (2010) 1149-1159. 